\title{
Optimized chronomodulated dual release bilayer tablets of fexofenadine and montelukast: quality by design, development, and in vitro evaluation
}

\author{
Bhupendra Singh ${ }^{1 *}$, Geetanjali Saini ${ }^{1}$, Manish Vyas ${ }^{2}$, Surajpal Verma ${ }^{2}$ and Sourav Thakur ${ }^{3}$
}

\begin{abstract}
Background: The conventional oral dosage forms are not effective in dealing with chronopathological conditions, such as nocturnal asthma. Therefore, there is an unmet need to develop a delivery system that can deliver drug as per the chronopharmacology of the diseases. The purpose of the study is to use quality by design $(\mathrm{QbD})$ technique and pulsatile principles for the development of Eudragit-coated dual release bilayer tablets. The dual layer consists of immediate release layer of fexofenadine $\mathrm{HCl}$ and sustained release layer of montelukast sodium.

Results: The quality target product profile of the formulation was developed, and the critical quality attributes were identified. Three-level, three-factor Box-Behnken design was used for the optimization of the bilayer tablets. Based on the design, a total of 13 formulation combinations (F1-F13 and M1-M13) were made having acceptable micromeritic properties. The developed immediate and sustained release layers were evaluated for physicochemical properties. Depending upon the value of the diffusion exponent, the Fickian diffusion mechanism is dominant among immediate and sustained release tablet layers. Response curve for immediate release layer showed that concentrations of sodium starch glycolate and sodium bicarbonate had a negative effect on disintegration time and a positive effect on drug release. For sustained release tablet layer, concentrations of HPMC E 5 LV and magnesium stearate had a significant effect on drug release. The ANOVA and diagnostic plots confirmed the significance and goodness of fit of the used model. Based on desirability plot values, optimized formulation was developed and coated with Eudragit coat. The coated bilayer tablet showed met the requirement of providing an immediate release during the first hour and a sustained release action for a period of more than $8 \mathrm{~h}$ after passing the gastric region.
\end{abstract}

Conclusions: The formulation can be fruitful in curbing the menace of nocturnal asthma and providing a high degree of patient compliance as the patient will not have to wake up at night to take the medication.

Keywords: Chronotherapy, Box-Behnken design, Fexofenadine, Montelukast, Optimization, Tablet, Eudragit, Quality by design

\footnotetext{
* Correspondence: bhupendratomar81@gmail.com

${ }^{1}$ Abhilashi College of Pharmacy, Ner Chowk Road, Ner Chowk, Mandi,

Himachal Pradesh 175008, India

Full list of author information is available at the end of the article
} 


\section{Background}

Nocturnal asthma can be defined as a drop in the forced expiratory volume in $1 \mathrm{~s}$ (FEV1) of at least $15 \%$ in between the bedtime and awakening in patients who suffered from asthma [1]. There is an increase in bronchial hyper-reactivity at night along with a decrease in lung function. This happens due to the circadian changes in the body's cortisol levels during the night [2]. An examination was directed at 7729 patients with asthma keeping in mind the end goal to investigate the pervasiveness of nocturnal asthma symptoms. Results showed that $64 \%$ of the patients indicated nocturnal asthma symptoms no less than 3 times per week. About 26\% of 3015 patients associated with mild asthmatic condition awakened at the night [3]. In another study, 3129 patients with nocturnal asthma were investigated and about $94 \%$ of them showed dyspneic episodes between $10 \mathrm{pm}$ and 7 am [4]. Studies have shown that nocturnal asthma is associated with mortality and the majority of the sudden death occurs between midnight and 5 am $[5,6]$. The conventional dosage forms were found less effective in the management of nocturnal asthmatic attacks. Therefore, there is a need for a modified system in order to overcome the present limitations.

The pulsatile systems have shown positive outcomes in the management of ailment with chronopathalogy, such as nocturnal asthma [7]. The chronotherapeutic pulsatile systems release the drug in a pulsatile manner at a predetermine off-release period (lag time) in a specific site in order to emulate the chronopathological symptoms [8]. The bi- or multilayer drug delivery frameworks are gaining more acceptance due to various benefits, such as two different or same therapeutic entity can be delivered with different release profile, and therapeutic efficacy can be increased due to the synergistic effect of two drugs and reduces the dosing unit burden thus improving patient compliance [9-11]. To date, different technologies have been used in the development of the modified tablets, such as OROS $^{\circ}$, L-OROSTM, EN SO TROL, DUROS, and DUREDAS [9]. In the present investigation, Dual Release Drug Absorption System (DUREDAS) technology was used for the development of fexofenadine $\mathrm{HCl}$ - and montelukast sodiumloaded bilayer tablet.

In the development of any pharmaceutical product, the quality of the dosage form is of prime importance for regulatory bodies. Considering the specific end goal to maintain the quality within the product, the quality by design (QbD) approach has become mandatory by all regulatory bodies. The principle of $\mathrm{QbD}$ is described in the Q8 (R2) guideline of the International Conference on Harmonisation ( $\mathrm{ICH}$ ) as "a systematic approach to development that begins with predefined objectives and emphasizes product and process understanding and process control, based on sound science and quality risk management" [12]. Three ICH guidelines, ICH Q8 (pharmaceutical development), ICH Q9 (pharmaceutical risk management), and ICH Q10 (pharmaceutical quality systems), cover various aspects of $\mathrm{QbD}[13,14]$. The important elements of $\mathrm{QbD}$ include defining the objective, i.e., Quality Target Product Profile (QTPP), determination of critical quality attributes (CQAs), risk assessment, development of experimental design, implementation of the control strategy, and continuous improvement.

The present investigation is focused on the application of $\mathrm{QbD}$ for the development of chronomodulated dual release bilayer tablets. Bilayer tablets of fexofenadine $\mathrm{HCl}$ and montelukast sodium were developed. Montelukast sodium is a leukotriene receptor antagonist used for the treatment of asthma and seasonal allergies. Fexofenadine $\mathrm{HCl}$ is a second generation $\mathrm{H}$ 1 receptor antagonist or antihistamine used for the management of allergic rhinitis. In addition, fexofenadine $\mathrm{HCl}$ also has an anti-inflammatory effect due to mediators [15]. A combination therapy of antihistamines and antileukotrienes will show a synergistic effect for the better management of nocturnal asthma. The pulsatile principle was used for the time release of the drugs from each layer of the bilayer tablets. A three-factor, three-level Box-Behnken design was used for the design of experiment (DoE). The powder blends were assessed for their micromeritic properties and used for the development of bilayer tablets. The prepared two different core tablet layers (immediate and sustained layers) were evaluated for various parameters including drug release kinetics. The impact of formulation variables on disintegration time and drug release of two separate tablet layers was evaluated. The optimized layers were used to prepare bilayer tablet by direct compression. Finally, the bilayer tablet was coated with Eudragit S100 and evaluated for various parameters including in vitro drug release.

\section{Methods}

Materials

Fexofenadine $\mathrm{HCl}$ and montelukast sodium were purchased from Aspen Life Sciences, Amritsar, India. The polyvinylpyrrolidone K30 (PVP K30), microcrystalline cellulose, lactose monohydrate, magnesium stearate, and sodium starch glycolate were purchased from BB Chemicals, Aurangabad, India. Isopropyl alcohol, indigo carmine blue, starch, hydroxypropyl methylcellulose (HPMC E 5 LV), and phosphate buffer saline (PBS) were purchased from Loba Chemie Pvt. Ltd., Mumbai, India. All other chemicals are of analytical grade. 


\section{Drug-polymer compatibility studies}

The drug-drug and drug-polymer compatibilities were investigated using FTIR spectroscopy. The FTIR spectra were recorded for the drugs alone and in combination with polymers using the potassium bromide $(\mathrm{KBr})$ dispersion method. The drug and combination samples were added to $\mathrm{KBr}$ (1:1) and examined at the range of 400 to $4000 \mathrm{~cm}^{-1}$ with the resolution of $4 \mathrm{~cm}^{-1}$.

\section{Initial risk assessment}

The Quality Target Product Profile (QTPP) is an integral part of the quality by design (QbD) approach and has been described in ICH Q8 and Q9. In like manner, it is imperative to recognize the objective at a beginning period of the product development $[13,14]$. The QTPP incorporates item product attributes to guarantee that the item meets the base wanted quality particulars. The QTPP and CQAs for the bilayer tablet were determined in light of the past investigations and literature reviews.

\section{Experimental design}

In the present work, 13-run, 3 factor, 3-level BoxBehnken design (BBD) was used for creating second order polynomial models and analyzing quadratic response surfaces for optimizing the immediate and sustained release layers of core tablets using Design-Expert software (Trial version 11.0.5.0, Stat-Ease Inc., MN). The design was used for assessing the main, interaction, and quadratic effects of independent variables on dependent variables using the following quadratic model:

$$
Y=\beta_{0}+\beta_{1 A}+\beta_{2 B}+\beta_{3 C}
$$

where $Y$ is the dependent variable, $\beta_{0-3}$ are the regression coefficients of independent variables and their mutual interactions, and $A, B$, and $C$ are the independent variables [16]. The factors evaluated in the present work are concentrations of fexofenadine $\mathrm{HCl}(\mathrm{mg})$, sodium starch glycolate $(\mathrm{mg})$, and sodium bicarbonate $(\mathrm{mg})$ for the immediate release layer, and concentrations of montelukast sodium (mg), HPMC E 5 LV (mg), and magnesium stearate $(\mathrm{mg})$ for the sustained release layer at low, medium, and high values. The dependent variables/responses were drug release (\%) and disintegration time (seconds) for the immediate release layer and drug release (\%) for the sustained release layer. The variables and their levels used in the development and optimization of immediate and sustained release tablet layers are illustrated in Table 1.

\section{Micromeritic studies}

In view of the design of experiment (DoE), diverse powder blends were prepared and set up for the development of immediate release (F1-F13) and sustained release (M1-M13)

Table 1 Variables and their levels in Box-Behnken design for immediate and sustained release tablet layers

\begin{tabular}{|c|c|c|c|}
\hline \multicolumn{4}{|c|}{ Immediate release fexofenadine $\mathrm{HCl}$ tablet layer } \\
\hline & \multicolumn{3}{|l|}{ Levels } \\
\hline & -1 (low) & 0 (medium) & +1 (high) \\
\hline \multicolumn{4}{|l|}{ Independent variables } \\
\hline$A=$ fexofenadine $\mathrm{HCl}(\mathrm{mg})$ & 60 & 90 & 120 \\
\hline$B=$ sodium starch glycolate $(\mathrm{mg})$ & 5 & 12.5 & 20 \\
\hline$C=$ sodium bicarbonate & 10 & 15 & 20 \\
\hline \multicolumn{4}{|l|}{ Dependent variables } \\
\hline \multicolumn{4}{|l|}{ Constraints } \\
\hline$Y_{1}=$ drug release $(\%)$ & \multicolumn{3}{|l|}{ Maximize } \\
\hline$Y_{2}=$ disintegration time (seconds) & \multicolumn{3}{|l|}{ Minimize } \\
\hline \multicolumn{4}{|c|}{ Sustained release montelukast sodium tablet layer } \\
\hline & \multicolumn{3}{|l|}{ Levels } \\
\hline & -1 (low) & 0 (medium) & +1 (high) \\
\hline \multicolumn{4}{|l|}{ Independent variables } \\
\hline$A=$ montelukast sodium (mg) & 5 & 7.5 & 10 \\
\hline$B=H P M C(\mathrm{mg})$ & 15 & 30 & 45 \\
\hline$C=$ magnesium stearate & 2 & 3 & 4 \\
\hline \multicolumn{4}{|l|}{ Dependent variables } \\
\hline \multicolumn{4}{|l|}{ Constraints } \\
\hline$Y=$ drug release $(\%)$ & Maximize & & \\
\hline
\end{tabular}


tablet layers. The powder blends were dried and mixed properly before evaluating their micromeritic properties. The composition of the powder blends used for the development of immediate and sustained release tablet layers is illustrated in Table 2.

\section{Angle of repose $(\theta)$}

For the determination of the angle of repose, precisely measured powders $(6 \mathrm{~g})$ from each formulation (F1-F13 and M1-M13) were permitted to stream openly through a funnel fixed to a stand at a specific height $(h)$. The height of the funnel was set approximately just above the height of the heap. The radius $(r)$ and height $(h)$ of the powder heap were determined to calculate the angle of repose. The following formula was used to measure the angle of repose:

$$
\theta=\tan ^{-1}(h / r)
$$

where $\theta$ is the angle of repose, $h$ is the height of heap, and $r$ is the radius of the heap.

According to specifications of the monograph, the value of $\theta$ indicates the flowability of the powder blend: $\theta<25^{\circ}$, excellent; $25-30^{\circ}$, good; $30-40^{\circ}$, fair; $40-45^{\circ}$, poor; and $\theta>45^{\circ}$, very poor [17].

\section{Bulk density and tapped density}

Dry powder blends $(6 \mathrm{~g})$ from each formulation were gently shaken to break conceivable agglomerates present and then poured in a measuring cylinder $(50 \mathrm{ml})$. The initial volume was noted, and the cylinder was held at a height of $2.5 \mathrm{~cm}$ and allowed to fall at an interval of $2 \mathrm{~s}$. The tapping of the cylinder was continued until a constant volume was noticed. The process was repeated thrice $(n=3)$ for each formulation, and the average was taken. The following formula was used for the determination of bulk density (BD) and tapped density (TD):

$\mathrm{BD}=$ Weight of powder taken/Bulk volume of the packaging

$\mathrm{TD}=$ Weight of powder taken/Tapped volume of the packaging

\section{Compressibility index (Carr's index)}

Compressibility index (Carr's index) of the dry powder blends for immediate and sustained release tablet layers was calculated using the following formula:

$$
\text { Carr's index }=(\mathrm{TD}-\mathrm{BD}) / \mathrm{TD} \times 100
$$

Carr's index also indicates the flowability of the powder blend: $5-15 \%$, excellent; $12-16 \%$, good; $18-21 \%$, fair;

Table 2 Composition of powder blends for the development of immediate release fexofenadine $\mathrm{HCl}$ and sustained release

\begin{tabular}{|c|c|c|c|c|c|c|c|c|c|c|c|c|c|}
\hline \multicolumn{14}{|c|}{ Immediate release fexofenadine $\mathrm{HCl}$ tablet layer } \\
\hline Ingredients (mg) & $\mathrm{F} 1$ & F2 & F3 & F4 & F5 & F6 & F7 & F8 & F9 & F10 & F11 & F12 & F13 \\
\hline Fexofenadine $\mathrm{HCl}$ & 120 & 90 & 60 & 90 & 120 & 120 & 60 & 60 & 120 & 90 & 90 & 60 & 90 \\
\hline Microcrystalline cellulose & 15 & 15 & 15 & 15 & 15 & 15 & 15 & 15 & 15 & 15 & 15 & 15 & 15 \\
\hline Lactose monohydrate & 23 & 58 & 98 & 60.5 & 38 & 35.5 & 95.5 & 83 & 25.5 & 63 & 73 & 85.5 & 48 \\
\hline Sodium starch glycolate & 20 & 20 & 5 & 12.5 & 5 & 12.5 & 12.5 & 20 & 12.5 & 5 & 5 & 12.5 & 20 \\
\hline Sodium bicarbonate & 15 & 10 & 15 & 15 & 15 & 10 & 10 & 15 & 20 & 20 & 10 & 20 & 20 \\
\hline Starch & 5 & 5 & 5 & 5 & 5 & 5 & 5 & 5 & 5 & 5 & 5 & 5 & 5 \\
\hline Magnesium stearate & 2 & 2 & 2 & 2 & 2 & 2 & 2 & 2 & 2 & 2 & 2 & 2 & 2 \\
\hline Total weight & 200 & 200 & 200 & 200 & 200 & 200 & 200 & 200 & 200 & 200 & 200 & 200 & 200 \\
\hline \multicolumn{14}{|c|}{ Sustained release montelukast sodium tablet layer } \\
\hline Ingredients (mg) & M1 & M2 & M3 & M4 & M5 & M6 & M7 & M8 & M9 & M10 & M11 & M12 & M13 \\
\hline Montelukast sodium & 5 & 7.5 & 5 & 7.5 & 10 & 10 & 5 & 10 & 7.5 & 5 & 7.5 & 10 & 7.5 \\
\hline Microcrystalline cellulose & 15 & 15 & 15 & 15 & 15 & 15 & 15 & 15 & 15 & 15 & 15 & 15 & 15 \\
\hline Lactose monohydrate & 30.5 & 15 & 16.5 & 13 & 27.5 & 41.5 & 46.5 & 11.5 & 29 & 32.5 & 45 & 25.5 & 43 \\
\hline HPMC E 5 LV & 30 & 45 & 45 & 45 & 30 & 15 & 15 & 45 & 30 & 30 & 15 & 30 & 15 \\
\hline PVP K-30 & 15 & 15 & 15 & 15 & 15 & 15 & 15 & 15 & 15 & 15 & 15 & 15 & 15 \\
\hline Magnesium stearate & 4 & 2 & 3 & 4 & 2 & 3 & 3 & 3 & 3 & 2 & 2 & 4 & 4 \\
\hline Indigo carmine blue & 0.5 & 0.5 & 0.5 & 0.5 & 0.5 & 0.5 & 0.5 & 0.5 & 0.5 & 0.5 & 0.5 & 0.5 & 0.5 \\
\hline Total weight & 100 & 100 & 100 & 100 & 100 & 100 & 100 & 100 & 100 & 100 & 100 & 100 & 100 \\
\hline
\end{tabular}
montelukast sodium tablet layer 
$23-35 \%$, poor; $33-38 \%$, very poor; and $>40 \%$, extremely poor [18].

\section{Hausner's ratio}

Hausner's ratio of dry powder blends for immediate and sustained release tablet layers was determined by the following formula:

$$
\text { Hausner's ratio }=\mathrm{TD} / \mathrm{BD}
$$

The values lesser than 1.25 indicate good flow, whereas values greater than 1.25 indicate a poor flow. Values between 1.25 and 1.5 are considered as average flow, and generally, a glidant has to be added for improving the flow properties [19].

\section{Immediate and sustained release tablet layers Development of tablet layers}

The powder blends with different combinations were used for the development of immediate and sustained release tablet layers. The ingredients were first passed through sieve number 44 to get a uniform particle size. All the ingredients except magnesium stearate were mixed in a mortar. Magnesium stearate was added at the last step and mixed well. The powder blends were then taken to the tablet punching machine. A three-punch hand-operated Trover Pharma Mach tablet punching machine was used for direct compression of the powder blends to get final tablet layer formulations.

\section{Evaluation of tablet layers}

A total of ten tablet layers $(n=10)$ from the batch of two different tablet layers (immediate and sustained) were randomly selected for the evaluation of various properties, such as hardness, percentage of friability, and weight variation. In addition, the tablet layers were also evaluated for the disintegration test for the immediate release layer, in vitro drug dissolution, and release kinetics. Disintegration test was performed using an altered disintegration method with six tablets $(n=6)$. The USP disintegration test apparatus was maintained at a temperature of $37 \pm 0.5^{\circ} \mathrm{C}$ in phosphate buffer saline (PBS, pH 6.8). The tablets were positioned in the baskets of the apparatus, and the time taken for complete tablet disintegration was noted [20]. The in vitro drug dissolution of the prepared tablet layer formulations was studied using eight-station USP type-II dissolution test apparatus maintained at a temperature of $37 \pm 0.5^{\circ} \mathrm{C}$. The study was carried out in $900 \mathrm{ml}$ of PBS (pH 6.8). The study was performed for $60 \mathrm{~min}$ for the immediate release tablet layer of fexofenadine $\mathrm{HCl}$, while it was performed for $8 \mathrm{~h}$ for sustained release tablet layer of montelukast sodium [21]. Aliquots were withdrawn after a predetermined time interval, and an equal volume of fresh buffer was added into the basket after each withdrawal. The absorbance of the aliquots was taken at $259 \mathrm{~nm}$ for fexofenadine $\mathrm{HCl}$ and at $285 \mathrm{~nm}$ for montelukast sodium simultaneously using a validated UV spectrophotometer. For drug release kinetics studies, different models, zero order, first order, Higuchi, and Korsmeyer-Peppas models, were used.

\section{Statistical optimization}

The impact of factors on the tablet properties was assessed through response surface plot (3D) and contour plot (2D) and generated from Design-Expert software. Statistical model validation involved assessing statistical parameters of $F$ value, correlation coefficient $\left(R^{2}\right)$, adjusted $R$-squared $\left(R^{2} \mathrm{Adj}\right)$, predicted $R$ squared ( $R^{2}$ Pred), predicted residual error sum of squares (PRESS), and adequate precision (AP) generated by ANOVA provision to ascertain model sufficiency and adequacy. An $F$ value with $p<0.05$ implied the significance of the model. A difference of less than 0.2 between $R^{2}$ Adj and $R^{2}$ Pred would prove that both values were in reasonable agreement with each other. Statistical validation of polynomial equations was done by assessing ANOVA specifications. Optimal values of the variables were then estimated using the numerical and graphical optimization tool by providing a set criterion of desirability to the software. A measure of fit was provided by PRESS statistics with a PRESS statistic of smaller value being preferred. Design-Expert software developed diagnostic plots like externally studentized residuals vs. predicted plot, predicted vs. actual plot, normal probability plot, and externally studentized residuals vs. run number plot which were analyzed to check if the points fell on the diagonal in normal probability plot and if they lay within the described limits or not.

\section{Optimized bilayer tablet}

Based on the optimized values of variables obtained, bilayer tablets of fexofenadine $\mathrm{HCl}$ and montelukast sodium were prepared by direct compression of tablet layers. Powder blends of both layers were prepared separately. The immediate release fexofenadine $\mathrm{HCl}$ powder blend was first poured into the die of the tablet punching machine. Tablets of the first layer were punched at a low compression force. Over this punched layer, sustained release montelukast sodium powder blend was poured. The compression force was increased, and both the layers were punched together to get bilayer tablets. The two layers could be clearly distinguished due to the addition of indigo carmine blue in the sustained release tablet layer. The 
developed bilayer tablet was evaluated for various tablet parameters.

\section{Eudragit-coated bilayer tablet}

The bilayer tablets were meant to release the active constituents in the intestine after a lag time of $2 \mathrm{~h}$. To meet this objective, the prepared tablets were coated with a solution of Eudragit S100. Based on the literature survey and hit and trial method, a $5 \% \mathrm{w} / \mathrm{v}$ solution of Eudragit S100 solution was prepared using isopropyl alcohol and acetone (1:1) for coating the tablets. Dip coating technique was used for coating the bilayer tablet. The prepared tablets were first weighed and then transferred into a beaker containing 5\% Eudragit S100 solution prepared in a mixture of isopropyl alcohol: acetone $(1: 1)$. Talc $(5 \% \mathrm{w} / \mathrm{w})$ was also added to the coating solution to prevent adhering of tablets. In addition, polyethylene glycol (PEG 400, $1.5 \% \mathrm{w} / \mathrm{w}$ ) was added as a plasticizer [22]. The tablets were left in the beaker for $5 \mathrm{~min}$ and then taken out with the help of forceps. Following the dipping step, the tablets were placed in a glass plate (smeared with castor oil) for drying at a room temperature for 15 min. Finally, the tablets were dried at $60^{\circ} \mathrm{C}$ in an oven for $30 \mathrm{~min}$ repeatedly, till the desired weight gain of the tablets was obtained. During drying step, the tablets were rotated occasionally. The dried coated tablets were again weighed to determine the weight of the coating layer.

Gradient pH dissolution method was used for the evaluation of drug release from the prepared coated bilayer tablets that were meant to release in the intestine [23]. For dissolution studies, USP dissolution apparatus II (paddle type) was used at $50 \mathrm{rpm}$ and a temperature of $37 \pm 0.5^{\circ} \mathrm{C}$. Eight-station LAB INDIA DS 8000 dissolution apparatus was used for the study. Six coated bilayer tablets, each containing fexofenadine $\mathrm{HCl}(60$ $\mathrm{mg}$ ) and montelukast sodium $(6.35 \mathrm{mg})$, were placed in individual vessels of the dissolution apparatus and studied. For the first $2 \mathrm{~h}$, the dissolution study was carried out in $900 \mathrm{ml}$ of $\mathrm{pH} 1.2 \mathrm{HCl}$ buffer at $50 \mathrm{rpm}$ and a temperature of $37 \pm 0.5^{\circ} \mathrm{C}$ considering the average gastric emptying time is $2 \mathrm{~h}$. Aliquots of $5 \mathrm{ml}$ were withdrawn every $5 \mathrm{~min}$, and an equal volume of fresh $\mathrm{HCl}$ buffer ( $\mathrm{pH} 1.2)$ was added into the dissolution vessel. After $2 \mathrm{~h}$, the volume of the dissolution medium was replaced with phosphate buffer $(900 \mathrm{ml}$, $\mathrm{pH}$ 6.8). The study was continued in the medium for the next $8 \mathrm{~h}$. Aliquots of $5 \mathrm{ml}$ were withdrawn at predetermined time intervals, and an equal volume of fresh phosphate buffer ( $\mathrm{pH}$ 6.8) was added into the dissolution vessel. The absorbance of each of the withdrawn aliquots of fexofenadine $\mathrm{HCl}$ and montelukast sodium was estimated simultaneously at two different wavelengths of $259 \mathrm{~nm}$ and $285 \mathrm{~nm}$. The UV method was already validated for the estimation of these two drugs. However, the entire validation is not mentioned in this paper as the validation study is a part of our next manuscript.

\section{Results \\ Compatibility studies}

To date, studies have been shown that the possible drug-drug/drug-excipient interaction can affect the stability of the drug and its release from the developed formulation $[24,25]$. The FTIR spectrum of the fexofenadine $\mathrm{HCl}$ showed various characteristic bands, such as $-\mathrm{OH}$ (alcohol) at $3298.3 \mathrm{~cm}^{-1},-\mathrm{CH}$ stretching (alkane) at $2934.7 \mathrm{~cm}^{-1},-\mathrm{OH}$ (carboxylic acid) at $2672.4 \mathrm{~cm}^{-1}$, $\mathrm{CO}$ stretching (carboxylic acid) at $1712.2 \mathrm{~cm}^{-1}, \mathrm{C}=\mathrm{C}$ stretching (aromatic ring) at $1451.4 \mathrm{~cm}^{-1}$ and 1403.2 $\mathrm{cm}^{-1}, \mathrm{CN}$ stretching (amine) at $1279.8 \mathrm{~cm}^{-1}$, and $\mathrm{CO}$ stretching (carboxylic acid) at $1166.0 \mathrm{~cm}^{-1}$ (Fig. 1a). In addition, the FTIR spectrum of the montelukast sodium has also showed various characteristic bands, such as $\mathrm{NH}$ stretching (amine) at $3309.9 \mathrm{~cm}^{-1}, \mathrm{C}-\mathrm{H}$ stretching (alkane) at $2979.1 \mathrm{~cm}^{-1}, \mathrm{C}=\mathrm{C}$ stretching (alkene) 1603.1 $\mathrm{cm}^{-1}, \mathrm{C}=\mathrm{C}$ stretching (aromatic ring) at $1491.0 \mathrm{~cm}^{-1}$, $\mathrm{CN}$ stretching (amine) at $1403.2 \mathrm{~cm}^{-1}$, and CO stretching (carboxylic acid) at $1137.0 \mathrm{~cm}^{-1}$ (Fig. 1b). The FTIR spectrum of the physical mixture of the drug (fexofenadine $\mathrm{HCl}$ and montelukast sodium) has shown all the characteristic bands of the individual drugs that indicate the compatibility between them (Fig. 1c).

The FTIR spectrum of the drug and polymer physical mixture was also recorded in order to evaluate any possible interaction among them. The FTIR spectrum of the fexofenadine $\mathrm{HCl}$ and sodium starch glycolate showed all the characteristic bands of the fexofenadine $\mathrm{HCl}$ (Fig. 2a). The FTIR spectrum of the montelukast and HPMC E 5 LV showed all the characteristic bands of the montelukast sodium (Fig. 2b). The FTIR spectrum of fexofenadine $\mathrm{HCl}$ and Eudragit S100 has shown the characteristic bands of the drug. The FTIR spectrum of montelukast sodium and Eudragit S100 showed characteristic bands of the drug (Fig. 2c, d). The FTIR studies has reviled that the drug and excipients were compatible with each other and suitable for the formulation development.

\section{Initial risk assessment}

This initial risk assessment was based on prior knowledge, experience, and published literature. The risk variables were indicated as high, medium, and low (Table 3). Based on currently available knowledge, medium risk variables can be considered acceptable. The Quality Target Product Profile (QTPP) and critical quality attributes (CQAs) for the bilayer tablet, such as dosage form, 

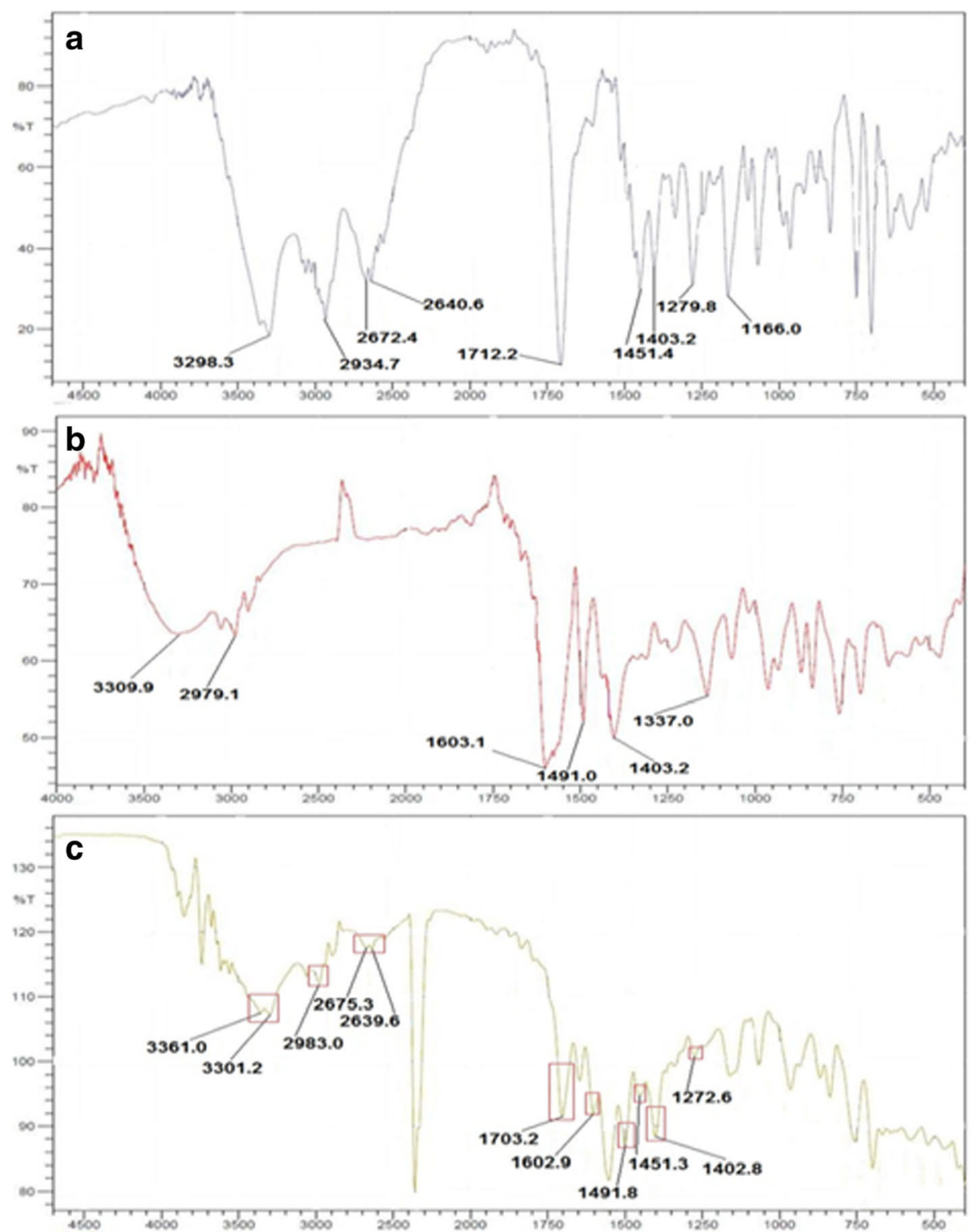

Fig. 1 FTIR spectrum of a fexofenadine $\mathrm{HCl}$, b montelukast sodium, and $\mathbf{c}$ physical mixture of fexofenadine $\mathrm{HCl}$ and montelukast sodium

dosage design, route of administration, appearance, size, weight variation, hardness, friability, and dissolution, were considered. For this study, only dissolution rate and disintegration time were considered.

\section{Experimental design}

A 3-factor, 3-level BBD was used for the optimization of immediate release fexofenadine $\mathrm{HCl}$ and sustained release montelukast sodium tablet layers. The independent variables selected for immediate release layers were fexofenadine $\mathrm{HCl}(\mathrm{mg})$, sodium starch glycolate (mg), and sodium bicarbonate (mg). The independent variables selected for sustained release layers were montelukast sodium (mg), HPMC E $5 \mathrm{LV}$ (mg), and magnesium stearate $(\mathrm{mg})$. The effect of independent variables was investigated on the disintegration time and drug release of tablet layers (Table 1). A total of 13 different powder compositions (F1-F13 and M1-M13) were prepared for the development of immediate and sustained release tablet layer as per the BBD (Table 2). Before they used for the development of the immediate and sustained release tablet layers, these powder blends were first evaluated for their micromeritic properties. The properties studied were the angle of repose $(\theta)$, 

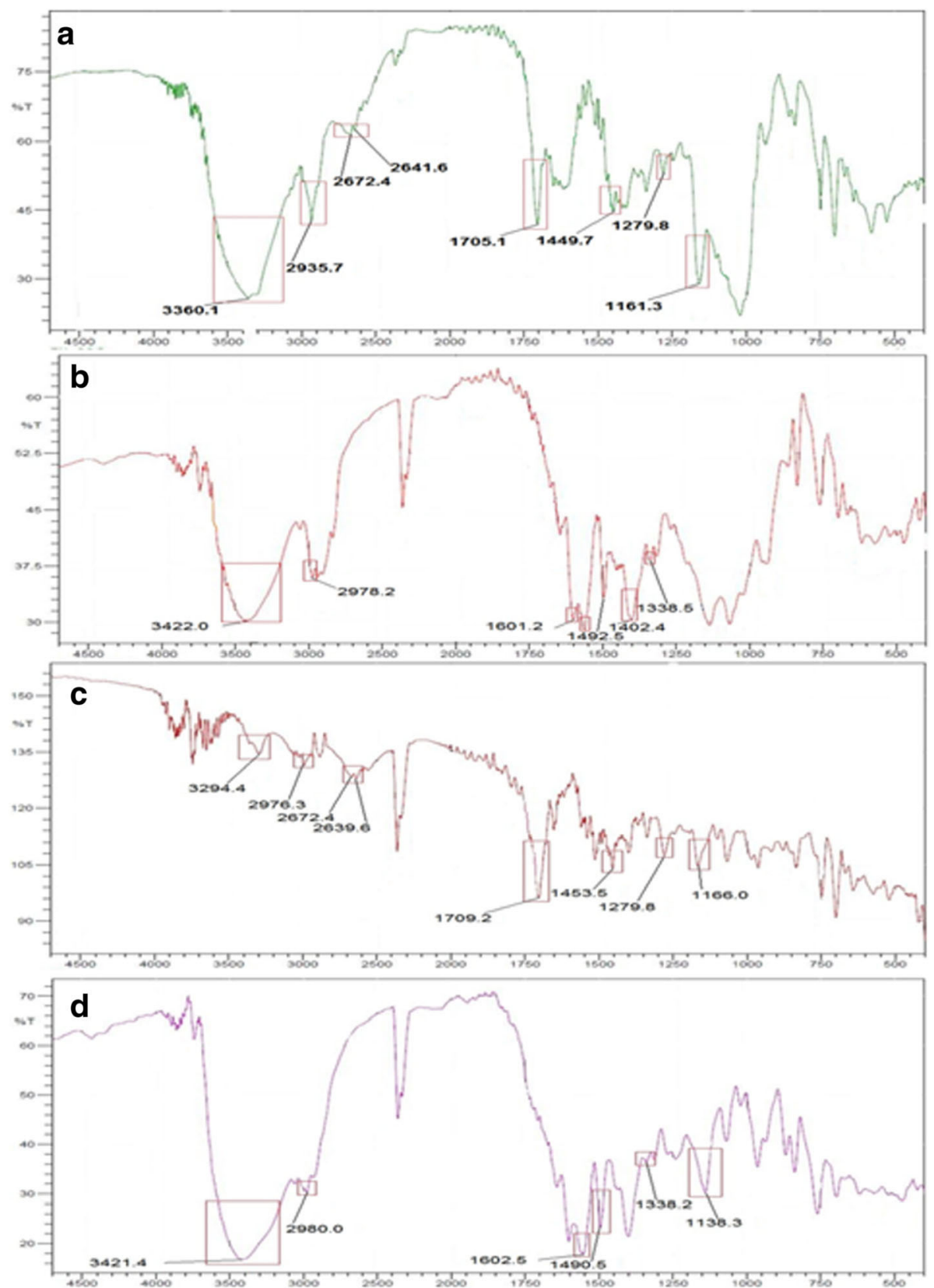

Fig. 2 FTIR spectrum of a fexofenadine $\mathrm{HCl}$ and sodium starch glycolate, $\mathbf{b}$ montelukast sodium and HPMC E 5 LV, c fexofenadine HCl and Eudragit S100, and d montelukast sodium and Eudragit S100

bulk density, tapped density, Carr's index, and Hausner's ratio (Fig. 3).

\section{Evaluation of the tablet layers}

The prepared powder blends were evaluated for micromeritic properties followed via development of immediate release tablet layers of fexofenadine $\mathrm{HCl}$ (F1-F13) and sustained release tablet layers of montelukast layers (M1-M13). The tablet layers were evaluated for various parameters, such as hardness, percentage of friability, weight variations, disintegration time of the immediate release layer, and percentage of drug release (Fig. 4). The developed immediate and sustained release tablet layers were also evaluated for diffusion release kinetics. Depending upon the value of the diffusion exponent $(n)$, the Fickian diffusion mechanism is dominant among sustained release formulations. 
Table 3 Initial risk assessments for formulation development based on prior knowledge, experience, and published literature

\begin{tabular}{|c|c|c|c|c|c|c|c|c|c|c|}
\hline \multirow{3}{*}{$\begin{array}{l}\text { Drug product } \\
\text { CQAs }\end{array}$} & \multicolumn{10}{|c|}{ Formulation variables } \\
\hline & \multicolumn{6}{|c|}{ Fexofenadine $\mathrm{HCl}$ layer } & \multicolumn{4}{|c|}{ Montelukast sodium layer } \\
\hline & $\begin{array}{l}\text { Sodium } \\
\text { bicarbonate }\end{array}$ & $\begin{array}{l}\text { Lactose } \\
\text { level }\end{array}$ & $\begin{array}{l}\text { Starch } \\
\text { level }\end{array}$ & $\begin{array}{l}\text { Sodium starch } \\
\text { glycolate level }\end{array}$ & $\begin{array}{l}\text { MCC } \\
\text { level }\end{array}$ & $\begin{array}{l}\text { Magnesium } \\
\text { stearate level }\end{array}$ & $\begin{array}{l}\text { HPMC E } 5 \text { LV } \\
\text { level }\end{array}$ & $\begin{array}{l}\text { PVP K30 } \\
\text { level }\end{array}$ & $\begin{array}{l}\text { Lactose } \\
\text { level }\end{array}$ & $\begin{array}{l}\text { Magnesium } \\
\text { stearate level }\end{array}$ \\
\hline Friability & Low & Medium & High & Medium & High & Medium & High & High & Medium & Medium \\
\hline Assay & Low & Low & Low & Low & Low & Low & Low & Low & Low & Low \\
\hline Hardness & Low & Medium & High & Medium & High & Low & High & High & Medium & Low \\
\hline $\begin{array}{l}\text { Weight } \\
\text { variation }\end{array}$ & Low & Low & Low & Low & Low & Low & Low & Low & Low & Low \\
\hline Dissolution & High & Medium & High & High & High & Medium & High & High & Medium & Medium \\
\hline
\end{tabular}

Low: the risk is broadly acceptable and requires no further investigation Medium: acceptable risk. Further investigation may be required for risk reduction High: unacceptable risk. Further investigation required for risk reduction

\section{Optimization of immediate release tablet layer Effect on disintegration time}

The initial model without transformation did not fit into the model as it had a high percentage error. Hence, based on the suggestion of the software, log transformation was applied for disintegration time and further analysis and validation were done based on ln (disintegration time). The factors affecting disintegration time were concentrations of fexofenadine $\mathrm{HCl}(A)$, sodium starch glycolate $(B)$, and sodium bicarbonate $(C)(p=$ 0.0094) as depicted from the given equation:

$$
\begin{aligned}
& \ln (\text { disintegration time }) \\
& =4.62+0.0093 \times A-1.37 \times B-0.0860 \\
& \quad \times C\left(r^{2}=0.9956\right)
\end{aligned}
$$

The observed disintegration time of immediate release fexofenadine $\mathrm{HCl}$ layers (F1-F13) varied from 21 to 421 $\mathrm{s}$ (minimum disintegration time of $21 \mathrm{~s}$ ). The predicted disintegration time values obtained by the model using the above equation were compared with observed values. A low percentage error of $<5 \%$ ascertained that the model has good predictability (Table 5). Based on the values and signs of the coefficients, it can be concluded that the concentration of fexofenadine $\mathrm{HCl}(A)$ had a negligibly small effect on disintegration time. However, the concentrations of sodium starch glycolate and sodium bicarbonate had a negative effect. It was observed that $\ln$ (disintegration time) increased rapidly with an increase in the concentration of sodium starch glycolate $(B)$, which can be attributed to the improved moisture absorption by sodium starch glycolate that results in massive volumetric increase leading to faster disintegration (Fig. 5a-d) [26].

\section{Effect on drug release}

The factors affecting the drug release (\%) were concentrations of fexofenadine $\mathrm{HCl}(A)$, sodium starch glycolate
$(B)$, and sodium bicarbonate $(C)$ as depicted from the given equation:

$$
\begin{aligned}
\mathrm{Q}+5 \%= & 73.07+0.4373 \times A+17.49 \times B \\
& +1.67 \times C\left(r^{2}=0.9255\right)
\end{aligned}
$$

The observed drug release in fexofenadine $\mathrm{HCl}$ layer varied from 50.5579 to $88.8778 \%$. The predicted values of drug release (\%) (Y1) obtained by the model using the above equation were compared with the observed values, and low percentage error proved that the designed model has good predictability (Table 5). The good fitting data was confirmed through the value of regression coefficient $\left(r^{2}\right)$ which was 0.9255 . Based on the values and signs of the coefficients, it can be concluded that all the three factors had a positive effect on drug release (\%). However, the concentration of API $(A)$ did not have a significant effect on drug release. The concentrations of sodium starch glycolate $(B)$ and sodium bicarbonate $(C)$ had a significant positive effect on drug release $(Y 1)$ (Fig. $5 \mathrm{e}-\mathrm{h}$ ). This can be due to the improved moisture absorption by sodium starch glycolate that results in massive volumetric increase leading to faster disintegration and hence faster dissolution rate. Sodium bicarbonate, being an effervescence agent, generates carbon dioxide leading to pressure build-up within the formulation and thus causing the fast release of components. It acted synergistically by absorbing moisture and facilitating drug release. These findings are in agreement with previous reports [27].

\section{Optimization of the sustained release tablet layer Effect on drug release}

The factors affecting the percentage of drug release were concentrations of montelukast sodium $(A)$, HPMC E 5 LV $(B)$, and magnesium stearate $(C)$ as depicted from the given equation: 

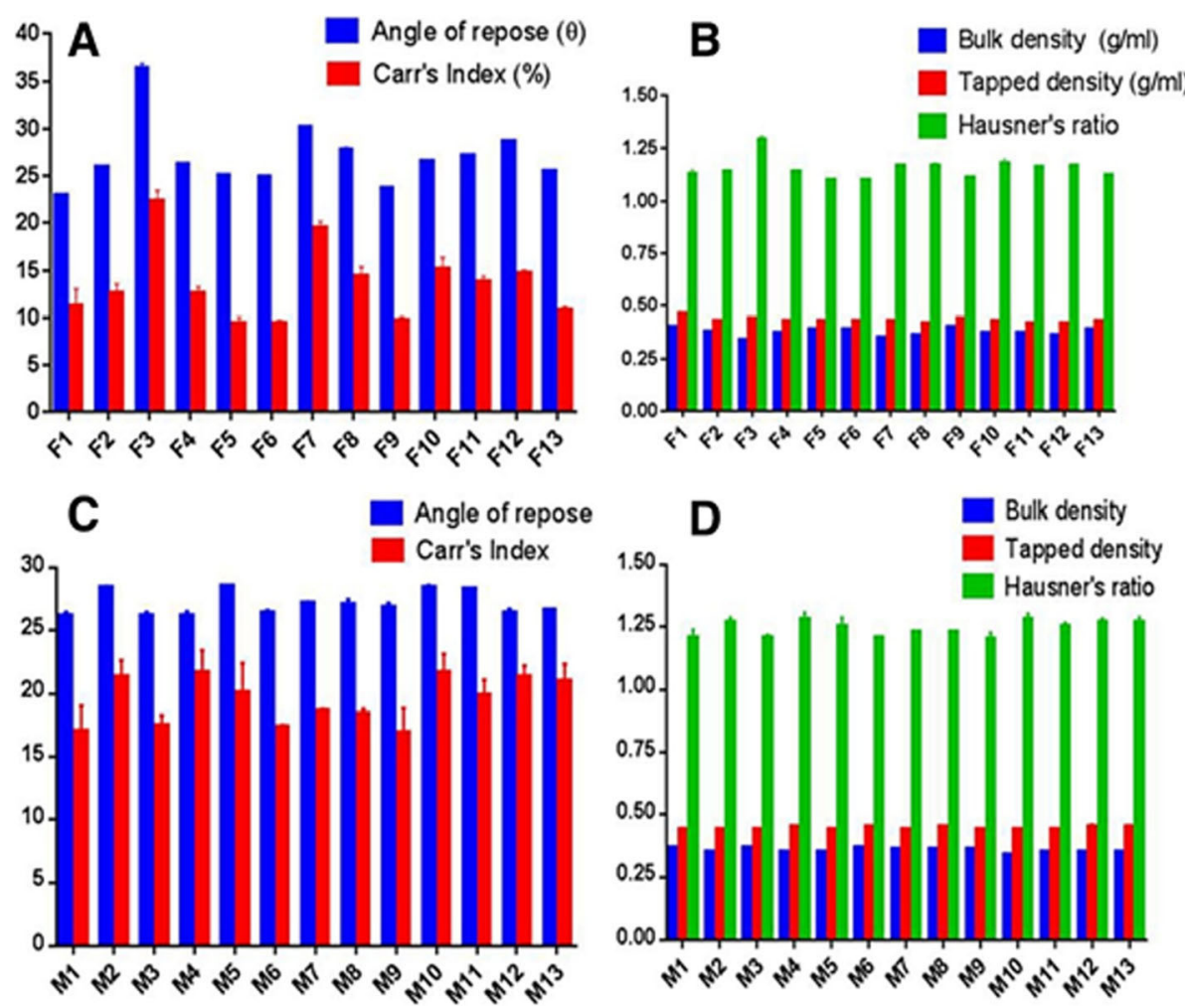

Fig. 3 Micromeritic properties of the powder blends. a, b The development of fexofenadine $\mathrm{HCl}$ immediate release tablet layers. $\mathbf{c}$, $\mathbf{d}$ The development of montelukast sodium sustained release tablet layers (mean \pm SD)

$$
\begin{aligned}
\% \text { drug release }= & 94.62-0.0544 \times A-5.87 \\
& \times B-1.09 \times C\left(r^{2}=0.9018\right)
\end{aligned}
$$

The observed drug release (\%) in montelukast sodium tablet layers varied from 85.6923 to $99.5331 \%$. The predicted values of drug release obtained by the model using the above equation were compared with the observed values, and low percentage error proved that the designed model has good predictability. The good fitting data was confirmed through the value of regression coefficient $\left(r^{2}\right)$ which was 0.9018 . The concentrations of HPMC E $5 \mathrm{LV}(B)$ and magnesium stearate $(C)$ had a significant effect on drug release. As the concentration of HPMC E $5 \mathrm{LV}$ was increased, there was a decrease in drug release (Fig. 5i-l). The mobility of the polymer chain gets enhanced in the presence of a solvent. As a result, a glassy matrix gradually transforms into a rubbery swollen gel. The higher concentrations of HPMC resulted in enhanced viscosity that retards the drug's diffusion coefficient [28]. The magnesium stearate is hydrophobic in nature and forms a film at the surface of API and excipients that causes the dissolution medium to stay on the surface, thus decreasing wettability of the formulation and thereby decreasing the dissolution rate [29] (Fig. 5i-1).

\section{Statistical assessment of formulation characteristics Statistical analysis for immediate release layer}

Model generated for $\ln$ (disintegration time) was found to be significant as suggested by the $F$ value of $684.94(p<0.0001)$. There was a reasonable agreement between the predicted $R^{2}$ Pred value of 0.9906 and adjusted $R^{2}$ Adj value of 0.9942 as the difference between the two was less than 0.2. Precision was found to be 61.2807, which was greater than 4, thus suggesting an adequate signal and the model could be used for navigating the design space. PRESS value of 0.1433 indicated that the model is fit. The model generated for drug release was found to be significant as suggested by the $F$ value of $37.28(p<0.0001)$. There was a reasonable agreement between the $R^{2}$ Pred value of 0.8457 and $R^{2}$ Adj value of 0.9007 as the difference between the two was less than 0.2. Adequate precision was found to be 14.6995, which was greater than 4, thus suggesting an adequate signal and the model could be used for navigating the design space. PRESS value of 411.80 indicated that the model is fit (Table 6).

\section{Statistical analysis for sustained release layer}

The model generated for the drug release (\%) was found to be significant as suggested by the $F$ value of 

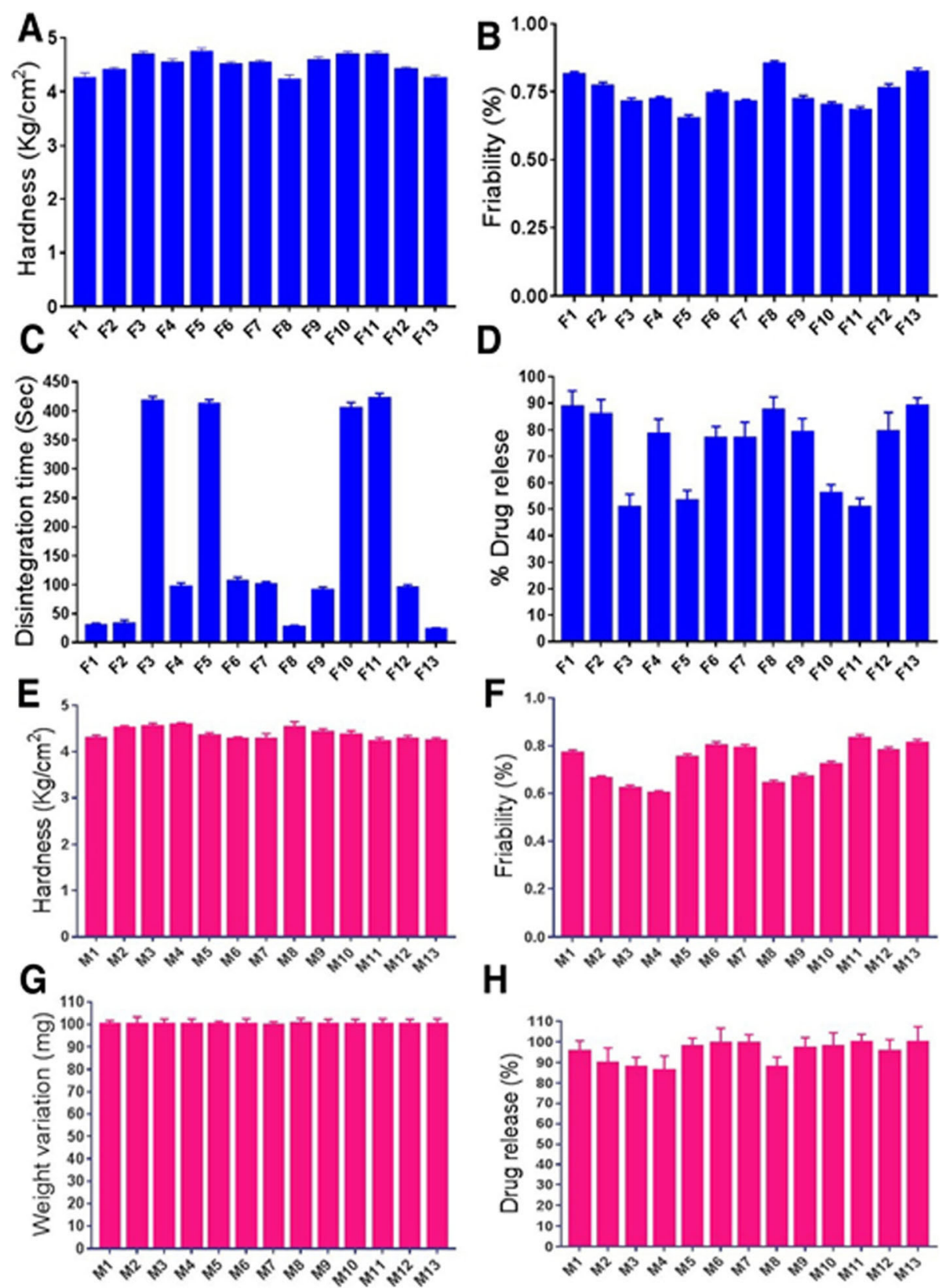

Fig. 4 Evaluation of immediate release fexofenadine $\mathrm{HCl}$ tablet layer. a Hardness $\left(\mathrm{kg} / \mathrm{cm}^{2}\right)$. b Friability (\%). c Disintegration time (seconds). $\mathbf{d}$ Drug release $(\mathrm{Q}+5 \%)$. Evaluation of sustained release montelukast sodium tablet layer. e Hardness $\left(\mathrm{kg} / \mathrm{cm}^{2}\right)$. $\mathbf{f}$ Friability $(\%)$. $\mathbf{g}$ Weight variation $(\mathrm{mg})$. $\mathbf{h}$ Drug release $(\mathrm{Q}+5 \%)($ Mean $\pm \mathrm{SD})$

27.54 ( $p$ value $<0.0001)$. There was a reasonable agreement between the predicted $R^{2}$ value of 0.7982 and adjusted $R^{2}$ value of 0.8690 as the difference between the two was less than 0.2 . The precision value was found to be 13.5002, which was greater than 4, thus suggesting an adequate signal and the model could be used for navigating the design space. PRESS value of 63.77 indicated that the model is fit (Table 6).

\section{Diagnostic analysis}

\section{Diagnostic analysis of immediate release layer}

The goodness of fit of the proposed model for disintegration time was investigated by plotting diagnostic plots (Fig. 6a-d) [30]. The normal probability plot of externally studentized residuals indicated that most of the colored points depicting values of disintegration time were located around the normal probability line, which 


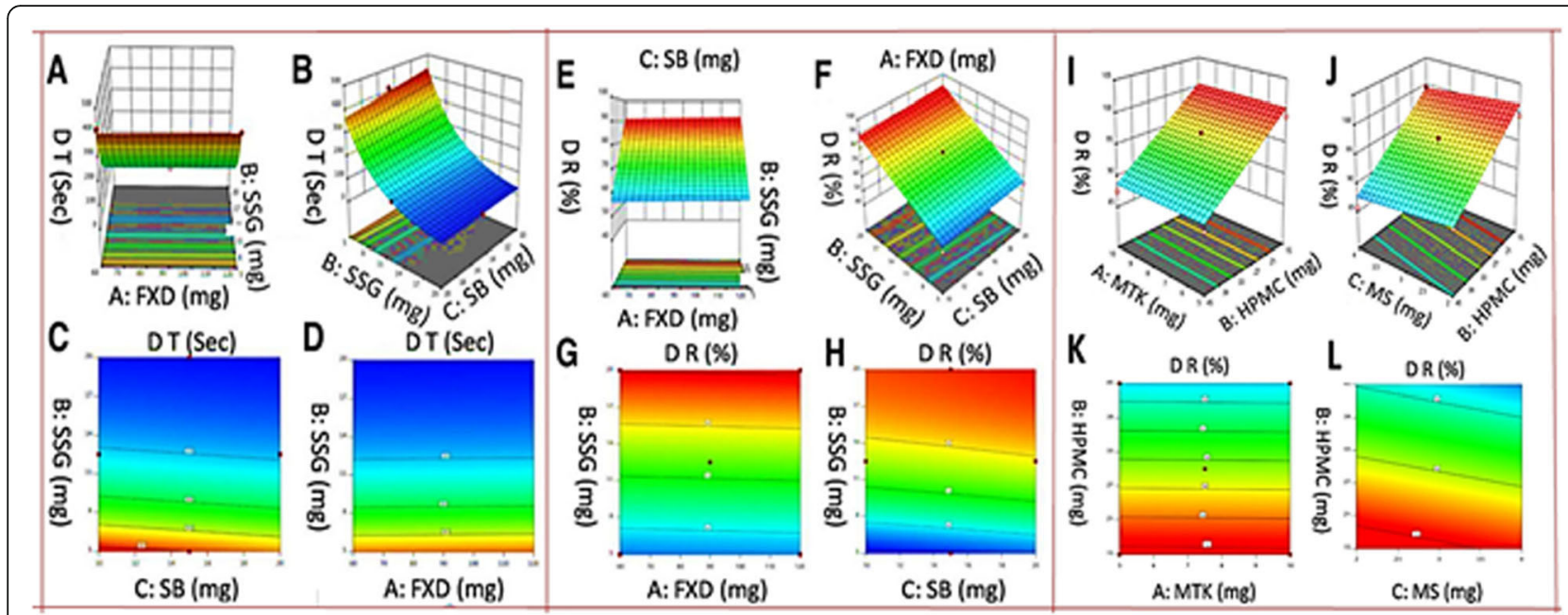

Fig. 5 Response surface and contour plots illustrating a-d effect of fexofenadine $\mathrm{HCl}$ (FXD), sodium starch glycolate (SSG), and sodium bicarbonate (SB) on disintegration time (DT); $\mathbf{e}-\mathbf{h}$ effect on drug release (DR); and $\mathbf{i}-\mathbf{I}$ effect of montelukast sodium (MTK), hydroxypropyl methylcellulose (HPMC), and magnesium stearate (MS) on drug release (DR)

proved the normality of residuals and suggested the relevant analysis of response data. The normality assumption for residuals was satisfied since the residuals are plotted around the straight line (Fig. 6a). The externally studentized residuals vs. predicted values plot revealed that the colored points of disintegration time lay within the set limits. The pattern of the plot showed the random distribution of studentized residuals in all the responses indicating that the assumption of constant variance was true (Fig. $6 \mathrm{~b}$ ). The residuals vs. run number plot explored the variables that may have influenced disintegration time during the experiment. All the points were lying within \pm 4.01 which indicated that there was no outlying observation throughout and consistency was observed in all the runs (Fig. 6c). The predicted vs. actual values plot revealed that the experimentally observed values of disintegration time were in close agreement with the predicted values (Fig. 6d).

The goodness of fit of the proposed model for the drug release was investigated by plotting diagnostic plots (Fig. 6e-h). The normal probability plot of externally studentized residuals indicated that most of the colored points depicting values of drug release $(\mathrm{Q}+5 \%)$ were located around the normal probability line, which proved the normality of residuals and suggested the relevant analysis of response data. The normality assumption for residuals was loosely satisfied in the linear model since the pattern of the residuals creates a little bit S-shaped curve (Fig. 6e). The externally studentized residuals vs. predicted values

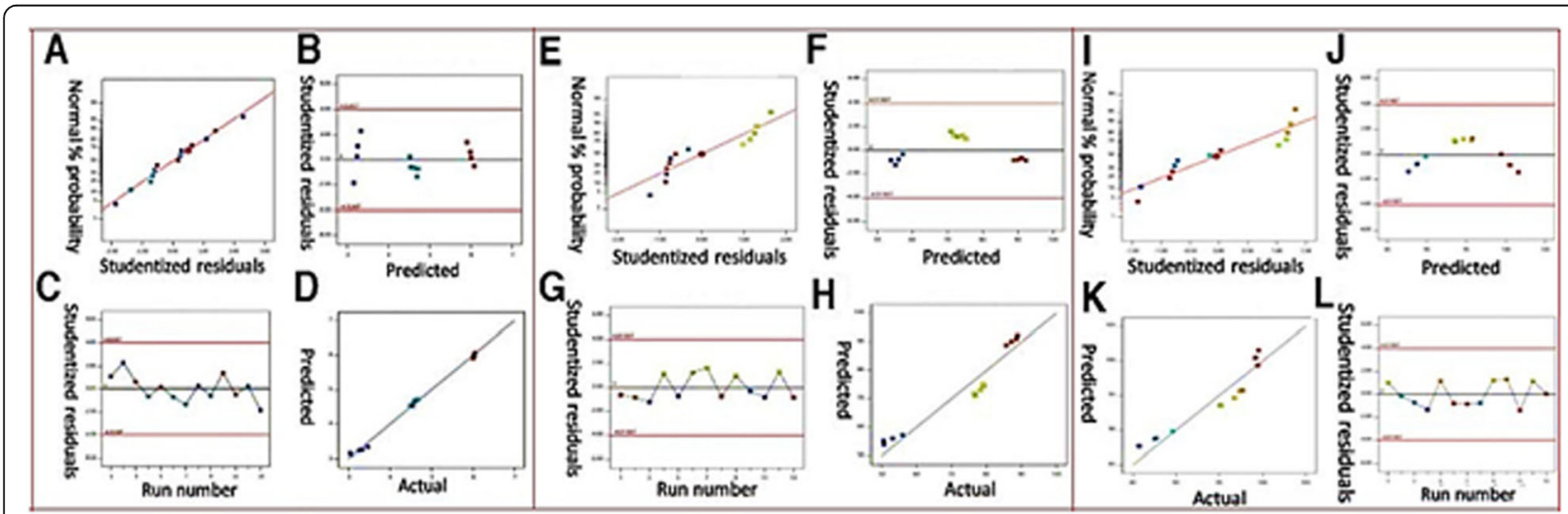

Fig. 6 Diagnostic plots for immediate release $(\mathbf{a}-\mathbf{h})$ and sustained release $(\mathbf{i}-\mathbf{I})$ tablet layer for disintegration time and drug release 
plot revealed that the colored points of $\mathrm{Q}+5 \%$ lay within the set limits. The pattern of the plot showed the random distribution of studentized residuals in all the responses indicating that the assumption of constant variance was true (Fig. $6 \mathrm{f}$ ). The residuals vs. run number plot explored the variables that may have influenced $\mathrm{Q}+5 \%$ during the experiment. All the points were lying within \pm 4.01 which indicated that there was no outlying observation throughout and consistency was observed in all the runs (Fig. 6g). The predicted vs. actual values plot revealed that the experimentally observed values of $\mathrm{Q}+5 \%$ were in close agreement with the predicted values (Fig. 6h).

\section{Diagnostic analysis of sustained release layer}

The goodness of fit of the proposed model for drug release from sustained release tablet layer was investigated by plotting diagnostic plots (Fig. 6i-l) [30]. The normal probability plot of externally studentized residuals indicated that most of the colored points depicting values of the percentage of drug release were located around the normal probability line. The normality assumption for residuals was loosely satisfied in the linear model (Fig. 6i). The externally studentized residuals vs. predicted values revealed that the colored points lay within the set limits (Fig. 6j). The predicted vs. actual values plot revealed that the experimentally observed values were in close agreement with the predicted values (Fig. 6k). Similar to the immediate release layer, that there was no outlying observation throughout and consistency was observed in all the runs (Fig. 6l).

\section{Optimization and validation \\ Optimization and validation of immediate release layer}

Design-Expert software explored the desirability function to obtain an optimized formulation, which was obtained using the set paradigm of maximum drug release and minimum disintegration time. Therefore, an additional batch of fexofenadine $\mathrm{HCl}$ immediate release layers was prepared for validation. The composition, point prediction, and confirmation of the experimental value lie within the limit. The response surface and contour plots for the immediate release fexofenadine $\mathrm{HCl}$ layer design suggested the values for fexofenadine $\mathrm{HCl}$ to be $60 \mathrm{mg}$, sodium bicarbonate to be $18.32 \mathrm{mg}$, and sodium starch glycolate to be $18.93 \mathrm{mg}$. The predicted value of the drug release according to the plot was $88.7258 \%$, and for disintegration time, the predicted value was $29.3966 \mathrm{~s}$ with a desirability of 0.819301 (Fig. 7a-f). The mean values obtained for drug release and the disintegration time of the optimized immediate release fexofenadine $\mathrm{HCl}$ layer were found to lie within the set limits. The layer was thus confirmed to be optimized.

\section{Optimization and validation of sustained release layer}

An additional batch of montelukast sodium-sustained tablet release layer was prepared for validation. For

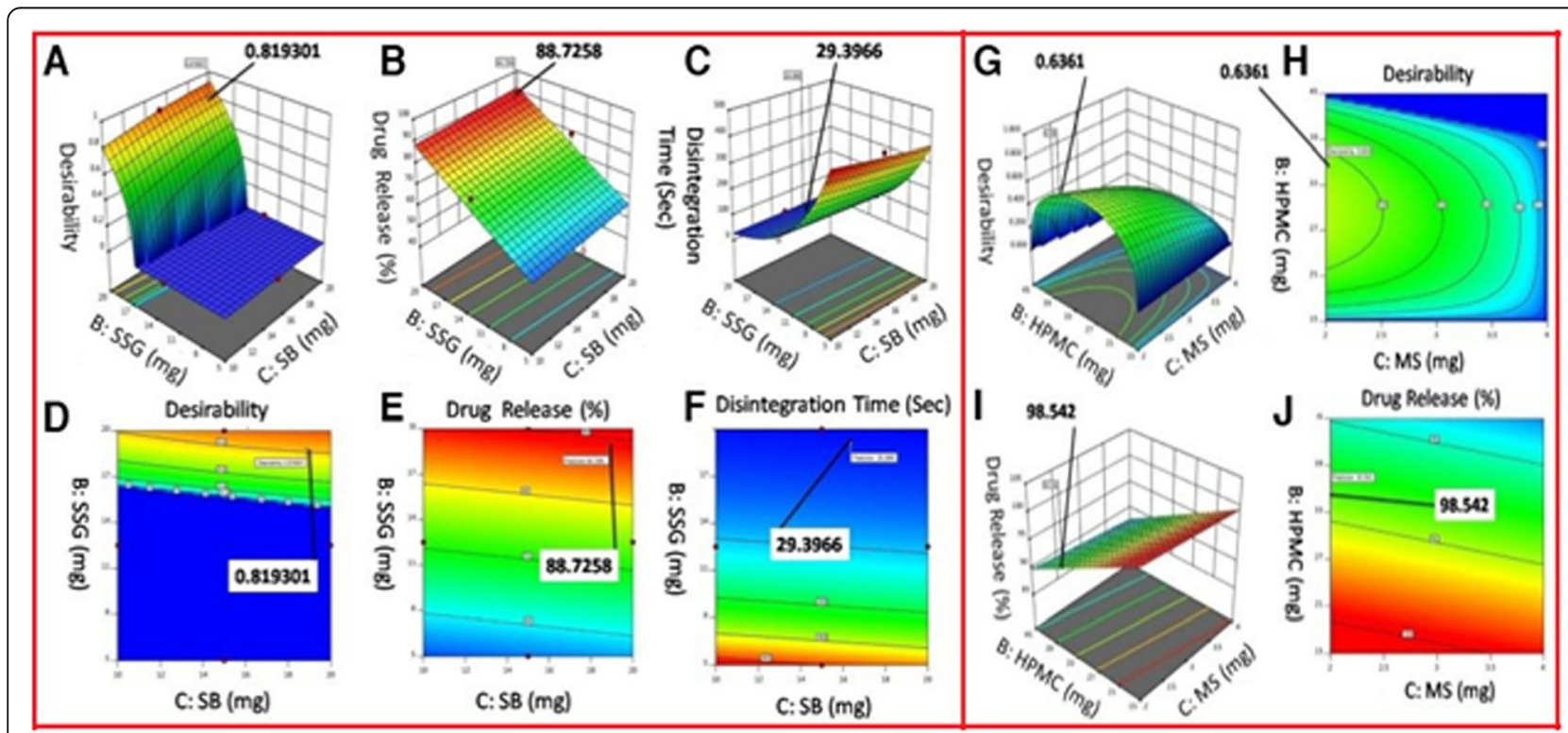

Fig. 7 The optimized immediate release tablet layer represented via desirability plot $(\mathbf{a}, \mathbf{d})$, correlating response factor plots for drug release (\%) (b, e) and disintegration time (seconds) (c, f). SSG, sodium starch glycolate; SB, sodium bicarbonate. The optimized sustained release layer tablet layer represented via desirability plot $(\mathbf{g}, \mathbf{h})$ and correlating response factor plots for drug release (\%) $(\mathbf{i}, \mathbf{j})$. HPMC, hydroxypropyl methylcellulose; MS, magnesium stearate 
the set composition of the sustained release layer, the predicted drug release and desirability were found to be $98.542 \%$ and 0.6361 (Fig. $7 \mathrm{~g}-\mathrm{j}$ ). The mean values obtained for drug release of the optimized sustained release montelukast sodium layer were found to lie within the set limits. The layer was thus confirmed to be optimized.

\section{Evaluation of optimized bilayer tablet}

The optimized immediate release tablet layer of fexofenadine $\mathrm{HCl}$ and sustained release tablet layers of montelukast sodium were used to develop bilayer tablet via direct compression (Fig. 8a). The bilayer tablets had a smooth surface. They were biconvex, elegant, and bicolored. The color distribution was uniform, and the two layers could be clearly distinguished based on the color difference. The immediate release fexofenadine $\mathrm{HCl}$ layer was blue in color, and the montelukast sodium sustained release layer was white in color (Fig. 8b). There were no chipping or mottling observed in any of the formulated tablets. The average thickness of the tablets was found to be $3.68 \pm 0.0067 \mathrm{~mm}$, and the average diameter was found to be $10.36 \pm 0.0074 \mathrm{~mm}$ (Fig. 8c, d). The mean hardness of the prepared tablets was $6.77 \pm 0.1033 \mathrm{~kg} / \mathrm{cm}^{2}$, while the observed percentage of friability was 0.76 , which was within the specified limit. The average weight of the tablets was $300 \pm 0.032 \mathrm{mg}$, and the weight variation was within limits.

The in vitro drug release was first performed in $\mathrm{pH}$ $1.2 \mathrm{HCl}$ buffer for $2 \mathrm{~h}$ and then in $\mathrm{pH} 6.8$ phosphate buffer. According to the scope of the study, drug release had to be observed after an initial lag time of 2 $\mathrm{h}$ when the drug would be in the gastric fluid. To meet this requirement, a coating of $5 \% \mathrm{w} / \mathrm{v}$ Eudragit S100 in isopropyl alcohol was applied. The in vitro dissolution data suggests no drug release up to 80 min of run time (Fig. 8f). Drug concentration was observed in $85 \mathrm{~min}$. However, the total amount of drug released till $120 \mathrm{~min}(2 \mathrm{~h})$ was only $4.08 \%$ for fexofenadine $\mathrm{HCl}$ and $0.12 \%$ for montelukast sodium, which are within the acceptable limit. Post- $2 \mathrm{~h}$ of dissolution, a burst release of fexofenadine $\mathrm{HCl}$ was observed with $97.65 \%$ drug release in $1 \mathrm{~h}$ ( $3 \mathrm{~h}$ from the beginning of the study). Only $4.47 \%$ montelukast sodium was released at the 3-h interval. The sustained release montelukast sodium layer continued to release drug steadily with $95.83 \%$ drug release at after $10 \mathrm{~h}$ of study. The formulation, thus, met the requirement of providing an immediate release during the first hour and a sustained release action for a period of $8 \mathrm{~h}$ after passing the gastric region.

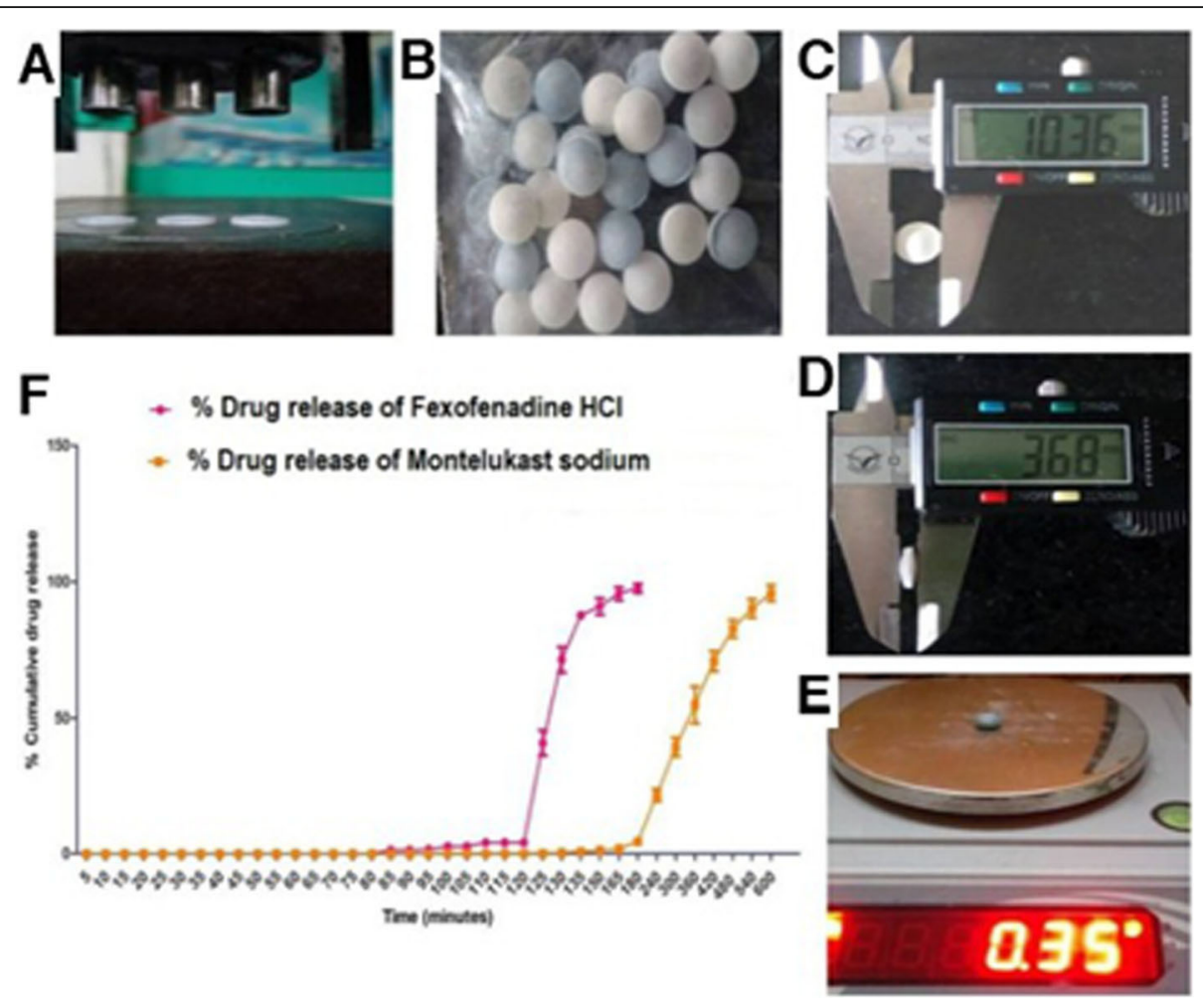

Fig. 8 Evaluation of optimized bilayer tablet. a Development of optimized bilayer tablet by direct compression method. b Optimized bilayer tablet. c Diameter of bilayer tablet. $\mathbf{d}$ Thickness of bilayer tablet. e Eudragit-coated bilayer tablet. $\mathbf{f}$ In vitro drug release from bilayer tablet 


\section{Discussion}

In the present investigation, we have developed Eudragit-coated chronomodulated time release bilayer tablet of fexofenadine $\mathrm{HCl}$ and montelukast sodium. Initially, the possible drug-drug and drug-excipient interactions were studies through IR spectroscopy. Results confirmed the drug-excipient compatibility and their suitability for the formulation development (Figs. 1 and 2 ). The initial risk assessment was performed through literature review. The QTPP and CQAs for bilayer tablet were established considering various parameters including dissolution rate and disintegration time (Table 3). In the fexofenadine $\mathrm{HCl}$ layer, starch and microcrystalline cellulose levels were found to have a high impact on friability, hardness, and dissolution. This is because of their binding properties. The microcrystalline cellulose is known to enhance tablet compressibility [31]. The sodium starch glycolate, being a super disintegrant, is a high-risk variable for disintegration followed by dissolution. In addition, sodium bicarbonate, which is an effervescence agent, is also a high-risk variable for disintegration and dissolution [32]. Other variables had medium to low risks on the CQAs. In the montelukast sodium layer, HPMC E $5 \mathrm{LV}$ and polyvinylpyrrolidone (PVP K30) were found to be high-risk variables. The magnesium stearate, being hydrophobic in nature, may influence the dissolution of the formulation [29]. Other variables had medium to low risk on the CQAs of the tablets. Based on the initial risk assessment, fexofenadine $\mathrm{HCl}$, sodium starch glycolate, and sodium bicarbonate levels in fexofenadine $\mathrm{HCl}$ layer, and montelukast sodium, HPMC E $5 \mathrm{LV}$, and magnesium stearate levels in the montelukast sodium layer were evaluated using a 3level, 3-factor Box-Behnken design (BBD).

For the optimization of immediate release fexofenadine $\mathrm{HCl}$ and sustained release montelukast sodium tablet layers, a 3-factor, 3-level BBD was used. For immediate release layers, fexofenadine $\mathrm{HCl}(\mathrm{mg})$, sodium starch glycolate $(\mathrm{mg})$, and sodium bicarbonate $(\mathrm{mg})$ were taken as independent variable. In the similar manner, independent variables selected for sustained release layers were montelukast sodium (mg), HPMC E 5 LV (mg), and magnesium stearate (mg) (Table 1). Based on the design, a total of 13 formulation combinations (F1-F13 and M1-M13) were made and evaluated for micromeritic properties (angle of repose $(\theta)$, bulk density, tapped density, Carr's index, and Hausner's ratio) (Table 2).

The powder blends for fexofenadine $\mathrm{HCl}$ immediate release layer (F1-F13) were evaluated for their micromeritic properties. It was observed that F1, F6, and F9 had excellent flow property, while F2, F4, F5, F8, F10, F11, F12, and F13 showed a good flow property (Fig. 3). However, F3 and F7 had the highest values for angle of repose, Carr's index, and Hausner's ratio and hence demonstrated a fair flow property (Fig. 3a, b). While there were variations in the bulk density of the formulations, the tapped density of all the formulations was found to be close to each other (Fig. 3b). It has been observed that as the concentration of lactose monohydrate increased, the flow property decreased. F1 had the best flow as it had the least amount of lactose monohydrate, while F3 showed a poor flow as compared to other formulations due to the presence of a high amount of lactose monohydrate. This is because lactose monohydrate has a poor flow property, and hence, it decreases the flow property of the formulation as its concentration in the formulation increases. Studies have shown that untreated lactose exhibited very poor powder flow. However, the flow properties of the lactose can be improved via intensive mechanical processing with magnesium stearate [33].

All the powder blends prepared for montelukast sodium-sustained release layer (M1-M13) showed good to fair flow property. Formulation M1 had the best flow property which can be confirmed through its observed angle of repose and Carr's index values (Fig. 3c). The flow property improved with an increase in the amount of magnesium stearate. However, the flow properties became constant with further increase in magnesium stearate. A similar effect has been observed in the previous studies where magnesium stearate at low and medium concentration increases the flow properties [34]. The flow properties of M3, M6, M7, M8, and M9, each containing $3 \mathrm{mg}$ of magnesium stearate, were superior to that of M2, M5, M10, and M11, having $2 \mathrm{mg}$ of magnesium stearate (Fig. 3c, d). The flow properties of M1, M4, M12, and M13, each containing $4 \mathrm{mg}$ magnesium stearate, did not differ much from M3, M6, M7, M8, and M9. The bulk density and tapped density values for all the formulations remained fairly constant (Fig. 3d). The powder blends were used for the development of immediate and sustained release tablet layers.

The powder blends were used for the development of immediate release tablet layers of fexofenadine $\mathrm{HCl}$ (F1F13) and sustained release tablet layers of montelukast layers (M1-M13). The developed tablet layers were evaluated for various parameters, such as hardness, percentage of friability, weight variations, disintegration time of the immediate release layer, and percentage of drug release.

The hardness of immediate release tablet layers ranged from 4.20 to $4.73 \mathrm{~kg} / \mathrm{cm}^{2}$. Maximum hardness was observed for F5, while F8 demonstrated the least hardness (Fig. 4a). All the tablet layers had acceptable hardness value. A direct relationship between percentage of friability and tablet hardness was observed. Tablets having high hardness value showed low percentage of friability and vice versa. The study has reported that there will be 
a decrease in the percentage of friability with an increase in the tablet hardness [35]. Thus, F5 had the least percentage of friability value of 0.65 , while F8 had a maximum percentage of friability of 0.85 (Fig. $4 \mathrm{~b}$ ). All the formulations were within the compendial limit of $<1 \%$. The harder the tablet, there will be fewer chances of chipping and breakage. Weights of immediate release tablet layers of all formulations were in close proximity to the actual value of $200 \mathrm{mg}$.

The disintegration time was found to decrease with an increase in the concentration of sodium starch glycolate and sodium bicarbonate (Fig. 4c). This is due to the swelling ability of sodium starch glycolate and the ability of sodium bicarbonate to liberate carbon dioxide upon coming in contact of water [36]. Disintegration time was also influenced by tablet hardness with tablets having low hardness showing low disintegration time [37]. Formulation F11 showed highest disintegration time. However, formulations F3, F5, and F10 have almost similar disintegration time (Fig. 4c). Formulation F13 had the least disintegration time of $21 \mathrm{~s}$ and the highest drug release $(88.88 \%)$ at $15 \mathrm{~min}$. On the other hand, formulation F11 had the maximum disintegration time of $421 \mathrm{~s}$ and a slow drug release of only $50.65 \%$ after 15 min (Fig. 4 d). According to the USP, an uncoated immediate release tablet should disintegrate completely within 5 to $30 \mathrm{~min}$. The immediate release compositions are selected in such a way they provide a disintegration time of less than about $30 \mathrm{~min}$, preferably about $20 \mathrm{~min}$ or less, and more preferably about $18 \mathrm{~min}$ or less. This means that F3, F5, F10, and F11 failed to meet the criteria. In addition, the USP also states that an immediate release tablet should release not less than $80 \%$ of its drug within 15 min. Considering the disintegration paradigm, only formulations F1, F2, F8, and F9 meet the necessary requirements. The hardness of the sustained release montelukast sodium tablets layers (M1-M13) ranged from 4.22 to $4.57 \mathrm{~kg} /$ $\mathrm{cm}^{2}$ (Fig. 4e). Maximum hardness was observed for M4, while M11 demonstrated the least hardness. All the tablets had acceptable hardness value. A direct relationship between percentage of friability and tablet hardness was observed. Tablets having high hardness value showed low percentage of friability and vice versa. Thus, M4 had the least percentage of friability value of 0.60 , while M11 had maximum percentage of friability of 0.83 . All the formulations were within the compendial limit of $<1 \%$ (Fig. 4f).

Weights of tablet layers of all formulations (M1-M13) were in close proximity to the actual value of $100 \mathrm{mg}$ (Fig. 4g). The concentration of HPMC E 5 LV and magnesium stearate influenced the percentage of drug release. It has been observed that the higher the concentration of HPMC E $5 \mathrm{LV}$, the slower was the drug release. The study has shown that HPMC can slow down the drug release from the tablet matrices. Similar observations were made in the case of varying concentrations of magnesium stearate. The HPMC forms a rubbery gel that retards drug dissolution, while the hydrophobic nature of magnesium stearate creates a barrier between the API and the outer environment [27]. M6, M7, M11, and M13 failed to sustain drug release for $8 \mathrm{~h}$. Formulation M10 showed the maximum drug release of $97.68 \%$ after $8 \mathrm{~h}$ (Fig. 4h). The immediate release and sustained release tablet layers were also evaluated for diffusion release kinetics. Among the immediate release fexofenadine $\mathrm{HCl}$ tablet layers, formulations F3 and F6 followed the Hixson-Crowell model suggesting that the dissolution occurred in planes parallel to the tablet surface. Formulation F4 followed the Korsmeyer-Peppas model, which is similar to the release from a polymeric matrix. All the other formulations were found to follow firstorder release kinetics suggesting that the release is concentration dependent. For immediate release fexofenadine $\mathrm{HCl}$ formulations, the value of the coefficient of correlation $\left(r^{2}\right)$ for the best fit model and diffusion exponent $(n)$ ranges from 0.8107 to 0.9864 and 0.334 to 0.390 , respectively. Depending upon the value of the diffusion exponent $(n)$, the Fickian diffusion mechanism is dominant among immediate release formulations (Table 4) [28].

For the optimization of immediate release tablet layer, the effect of variables on disintegration time and drug release was investigated through polynomial equation and response curves. The factors affecting disintegration time were concentrations of fexofenadine $\mathrm{HCl}(A)$, sodium starch glycolate $(B)$, and sodium bicarbonate $(C)$. The predicted disintegration time values obtained by the model using the above equation were compared with observed values. A low percentage error of $<5 \%$ ascertained that the model has good predictability (Table 5). The concentration of fexofenadine $\mathrm{HCl}(A)$ had a negligibly small effect on disintegration time. However, the concentrations of sodium starch glycolate and sodium bicarbonate had a negative effect. The disintegration of the tablet layer increased rapidly with an increase in the concentration of sodium starch glycolate $(B)$. This could be due to the improved moisture absorption by sodium starch glycolate that results in massive volumetric increase leading to faster disintegration. Sodium bicarbonate, being an effervescence agent, generates carbon dioxide leading to the pressure build-up within the formulation and thus causing the fast release of components. It also led to a faster disintegration time but not as much as sodium starch glycolate.

The effect of variables on the drug release from the immediate release tablet layer showed that the concentration of the drug $(A)$ did not have a significant effect on release. However, the concentrations of sodium 
Table 4 Diffusion release kinetics of immediate and sustained release tablet layers

\begin{tabular}{|c|c|c|c|c|c|c|c|}
\hline \multicolumn{8}{|c|}{ Immediate release fexofenadine $\mathrm{HCl}$ tablet layers } \\
\hline \multirow[t]{2}{*}{ Formulation } & \multicolumn{3}{|c|}{ Mathematical diffusion model } & \multicolumn{4}{|c|}{ Korsmeyer-Peppas model } \\
\hline & Best fit model & Equation & $r^{2}$ & $n$ & Equation & $r^{2}$ & Mechanism \\
\hline $\mathrm{F} 1$ & First order & $y=-0.0226 x+1.6196$ & 0.9078 & 0.334 & $y=0.2739 x-0.4522$ & 0.7702 & Fickian \\
\hline$F 2$ & First order & $y=-0.0064 x+1.8573$ & 0.8981 & 0.383 & $y=0.4323 x-0.8939$ & 0.8817 & Fickian \\
\hline F3 & Hixson-Crowell & $y=0.06 x+3.6677$ & 0.9864 & 0.389 & $y=0.4805 x-0.9347$ & 0.8964 & Fickian \\
\hline F4 & Korsmeyer-Peppas & $y=0.366 x-0.6456$ & 0.8535 & 0.371 & $y=0.366 x-0.6456$ & 0.8535 & Fickian \\
\hline F5 & First order & $y=-0.0137 x+1.739$ & 0.8803 & 0.359 & $y=0.3658 x-0.6449$ & 0.8266 & Fickian \\
\hline F6 & Hixson-Crowell & $y=0.0858 x+3.7455$ & 0.9653 & 0.376 & $y=0.3157 x-0.5529$ & 0.8656 & Fickian \\
\hline F7 & First order & $y=-0.0186 x+1.5783$ & 0.8216 & 0.328 & $y=0.2827 x-0.4703$ & 0.7561 & Fickian \\
\hline F8 & First order & $y=-0.0085 x+1.8671$ & 0.9391 & 0.389 & $y=0.4753 x-0.9229$ & 0.8967 & Fickian \\
\hline F9 & First order & $y=-0.0142 x+1.7476$ & 0.8879 & 0.364 & $y=0.3737 x-0.6561$ & 0.8377 & Fickian \\
\hline F10 & First order & $y=-0.01 x+1.8595$ & 0.9538 & 0.390 & $y=0.4587 x-0.87$ & 0.8977 & Fickian \\
\hline F11 & First order & $y=-0.0157 x+1.6437$ & 0.7914 & 0.343 & $y=0.3278 x-0.5575$ & 0.7895 & Fickian \\
\hline $\mathrm{F} 12$ & First order & $y=-0.0173 x+1.6354$ & 0.8107 & 0.344 & $y=0.3177 x-0.5354$ & 0.7922 & Fickian \\
\hline F13 & First order & $y=-0.0135 x+1.734$ & 0.8435 & 0.354 & $y=0.3859 x+0.6751$ & 0.8152 & Fickian \\
\hline \multicolumn{8}{|c|}{ Sustained release montelukast sodium tablet layers } \\
\hline \multirow[t]{2}{*}{ Formulation } & \multicolumn{3}{|c|}{ Mathematical diffusion model } & \multicolumn{4}{|c|}{ Korsmeyer-Peppas model } \\
\hline & Best fit model & Equation & $r^{2}$ & $n$ & Equation & $r^{2}$ & Mechanism \\
\hline M1 & Zero order & $y=0.0022 x-0.0631$ & 0.9827 & 0.423 & $y=1.6637 x-4.4097$ & 0.9752 & Fickian \\
\hline M2 & Zero order & $y=0.002 x-0.0624$ & 0.9834 & 0.428 & $y=1.9599 x-5.1506$ & 0.9864 & Fickian \\
\hline M3 & Zero order & $y=0.002 x-0.0616$ & 0.9823 & 0.420 & $y=2.0632 x-5.4212$ & 0.9673 & Fickian \\
\hline M4 & Zero order & $y=0.002 x-0.0606$ & 0.9808 & 0.416 & $y=2.1563 x-5.6404$ & 0.9585 & Fickian \\
\hline M5 & Zero order & $y=0.0022 x-0.0453$ & 0.9943 & 0.429 & $y=1.5957 x-4.177$ & 0.9881 & Fickian \\
\hline M6 & Hixson-Crowell & $y=0.0023 x+3.6243$ & 0.9926 & 0.419 & $y=1.075 x-2.5834$ & 0.9642 & Fickian \\
\hline M7 & Hixson-Crowell & $y=0.0022 x+3.6278$ & 0.9918 & 0.418 & $y=1.0974 x-2.6311$ & 0.9629 & Fickian \\
\hline M8 & Zero order & $y=0.0021 x-0.0395$ & 0.9862 & 0.421 & $y=2.0706 x-5.349$ & 0.9703 & Fickian \\
\hline M9 & Zero order & $y=0.0023 x-0.0505$ & 0.9891 & 0.420 & $y=1.8033 x-4.6924$ & 0.9683 & Fickian \\
\hline M10 & Zero order & $y=0.0023 x-0.0375$ & 0.9861 & 0.419 & $y=1.7073 x-4.4308$ & 0.9659 & Fickian \\
\hline M11 & Hixson-Crowell & $y=0.0023 x+3.6319$ & 0.9936 & 0.427 & $y=0.8891 x-2.1579$ & 0.9844 & Fickian \\
\hline M12 & Zero order & $y=0.0022 x-0.0495$ & 0.9908 & 0.427 & $y=1.7463 x-4.5495$ & 0.9832 & Fickian \\
\hline M13 & Hixson-Crowell & $y=0.0023 x+3.6209$ & 0.9971 & 0.420 & $y=1.0704 x-2.5704$ & 0.9674 & Fickian \\
\hline
\end{tabular}

starch glycolate $(B)$ and sodium bicarbonate $(C)$ had a significant positive effect on drug release (Y1) (Fig. 5e-h). Sodium bicarbonate, being an effervescence agent, generates carbon dioxide leading to pressure build-up within the formulation and thus causing the fast release of components. It acted synergistically by absorbing moisture and facilitating drug release.

For the optimization of sustained release tablet layer, the effect of variables on drug release was evaluated. Results showed that there was a decline in the drug release with increase in HPMC E 5 LV (Fig. 5i-l). The mobility of the polymer chain gets enhanced in the presence of a solvent. As a result, a glassy matrix gradually transforms into a rubbery swollen gel. The higher concentrations of
HPMC resulted in enhanced viscosity that retards the drug's diffusion coefficient. The magnesium stearate forms a film decreasing wettability of the formulation due to its hydrophobic nature and thereby decreasing the dissolution rate (Fig. 5i-l). The significance of the model used to evaluate the effect of variables on the performance of immediate and sustained release layers was evaluated through ANOVA analysis. The ANOVA and PRESS value suggested that the model generated was significant and fit for evaluation (Table 6).

The goodness of fit of the proposed model for immediate and sustained release tablet layer was investigated through diagnostic plots (Fig. 6a-d). The results through various diagnostic plots showed that the model used for 
Table 5 Experimental results and predicted values of response variables drug release $\left(Y_{1}\right)$ and disintegration time $\left(Y_{2}\right)$

\begin{tabular}{|c|c|c|c|c|c|c|}
\hline \multirow[t]{2}{*}{ Run } & \multicolumn{3}{|l|}{$Y_{1}$} & \multicolumn{3}{|l|}{$Y_{2}$} \\
\hline & Actual value & Predicted value & Percentage error & Actual value & Predicted value & Percentage Error \\
\hline 1 & 88.52 & 91.00 & -2.73 & 3.33 & 3.26 & 2.14 \\
\hline 2 & 85.62 & 88.89 & -3.68 & 3.47 & 3.33 & 4.20 \\
\hline 3 & 50.56 & 55.15 & -8.32 & 6.03 & 5.99 & 0.67 \\
\hline 4 & 78.17 & 73.07 & 6.98 & 4.56 & 4.62 & -1.30 \\
\hline 5 & 53.08 & 56.03 & -5.27 & 6.02 & 6.00 & 0.33 \\
\hline 6 & 76.54 & 71.84 & 6.54 & 4.66 & 4.72 & -1.27 \\
\hline 7 & 76.76 & 70.96 & 8.17 & 4.61 & 4.70 & -1.91 \\
\hline 8 & 87.11 & 90.12 & -3.33 & 3.26 & 3.24 & 0.62 \\
\hline 9 & 78.96 & 75.18 & 5.00 & 4.50 & 4.54 & -0.88 \\
\hline 10 & 55.96 & 57.26 & -2.27 & 6.00 & 5.91 & 1.52 \\
\hline 11 & 50.65 & 53.92 & -6.06 & 6.04 & 6.08 & -0.66 \\
\hline 12 & 79.16 & 74.31 & -6.79 & 4.54 & 4.53 & 0.22 \\
\hline 13 & 88.88 & 92.23 & -3.63 & 3.04 & 3.16 & -3.80 \\
\hline
\end{tabular}

the evaluation of variables on the properties of different tablet layers was fit for analysis. The optimized bilayer formulation with set paradigm of maximum drug release and minimum disintegration time was selected using desirability plots. The response surface and contour plots for the immediate release layer design suggested the values for fexofenadine $\mathrm{HCl}$ to be $60 \mathrm{mg}$, sodium bicarbonate to be $18.32 \mathrm{mg}$, and sodium starch glycolate to be $18.93 \mathrm{mg}$. The predicted value of the drug release according to the plot was $88.7258 \%$, and for disintegration time, the predicted value was $29.3966 \mathrm{~s}$ with a desirability of 0.819301 (Fig. 7a-f). Similarly, sustained tablet release layer was prepared with set composition. The predicted drug release and desirability were found to be

Table 6 ANOVA for (a) drug release $\left(Y_{1}\right)$ and (b) disintegration time $\left(Y_{2}\right)$

\begin{tabular}{|c|c|c|c|c|c|c|c|c|c|c|}
\hline \multirow[t]{2}{*}{ Source } & \multicolumn{5}{|l|}{$Y_{1}$} & \multicolumn{5}{|l|}{$Y_{2}$} \\
\hline & Sum of squares ${ }^{c}$ & $\mathrm{DF}^{\mathrm{d}}$ & Mean square ${ }^{e}$ & $F_{\text {value }}^{f}$ & $p$ value & Sum of squares & Degree of freedom & Mean square & F value & $p$ value \\
\hline Model & 2469.82 & 3 & 823.27 & 37.28 & $<0.0001^{*}$ & 15.16 & 3 & 5.05 & 684.94 & $<0.0001^{*}$ \\
\hline$A$ & 1.53 & 1 & 1.53 & 0.0693 & 0.7983 & 0.0007 & 1 & 0.0007 & 0.0937 & 0.7665 \\
\hline$B$ & 2445.91 & 1 & 2445.91 & 110.77 & $<0.0001^{*}$ & 15.10 & 1 & 15.10 & 2046.72 & $<0.0001^{*}$ \\
\hline C & 22.38 & 1 & 22.38 & 1.01 & 0.3404 & 0.0592 & 1 & 0.0592 & 8.02 & $0.0197^{*}$ \\
\hline Residual $^{a}$ & 198.74 & 9 & 22.08 & - & - & 0.0664 & 9 & 0.0074 & - & - \\
\hline Cor Total ${ }^{b}$ & 2668.55 & 12 & - & - & - & 15.22 & 12 & - & - & - \\
\hline \multirow[t]{2}{*}{ Source } & \multicolumn{10}{|l|}{$Y_{1}$} \\
\hline & \multicolumn{2}{|l|}{ Sum of square } & \multicolumn{2}{|c|}{ Degree of freedom } & \multicolumn{2}{|c|}{ Mean square } & \multicolumn{2}{|l|}{ F value } & \multicolumn{2}{|l|}{$p$ value } \\
\hline Model & 285.03 & & \multicolumn{2}{|l|}{3} & \multicolumn{2}{|l|}{95.01} & \multicolumn{2}{|l|}{27.54} & \multicolumn{2}{|l|}{$<0.0001^{*}$} \\
\hline$A$ & \multicolumn{2}{|l|}{0.0236} & \multicolumn{2}{|l|}{1} & \multicolumn{2}{|l|}{0.0236} & \multicolumn{2}{|l|}{0.0069} & \multicolumn{2}{|l|}{0.9358} \\
\hline$B$ & \multicolumn{2}{|l|}{275.59} & \multicolumn{2}{|l|}{1} & \multicolumn{2}{|l|}{275.59} & \multicolumn{2}{|l|}{79.88} & \multicolumn{2}{|l|}{$<0.0001^{*}$} \\
\hline C & \multicolumn{2}{|l|}{9.42} & \multicolumn{2}{|l|}{1} & \multicolumn{2}{|l|}{9.42} & \multicolumn{2}{|l|}{2.73} & \multicolumn{2}{|l|}{0.1328} \\
\hline Residual & \multicolumn{2}{|l|}{31.05} & \multicolumn{2}{|l|}{9} & \multicolumn{2}{|l|}{3.45} & \multicolumn{2}{|l|}{-} & \multicolumn{2}{|l|}{-} \\
\hline Cor Total & \multicolumn{2}{|l|}{316.08} & \multicolumn{2}{|l|}{12} & - & & - & & - & \\
\hline
\end{tabular}

*Significant $(p<0.05)$

${ }^{a}$ Residual sum of squares $=$ observed value - predicted value

${ }^{b}$ Cor total: variation amount around observation mean

'Sum of squares: the sum of the squared difference between the overall average and the variation amount

${ }^{\mathrm{d}} \mathrm{DF}$ (degrees of freedom): number of estimated parameters used to compute the sum of squares

${ }^{\mathrm{e}}$ Mean square: sum of squares/DF

${ }^{\mathrm{f}} F$ value: test for comparing mean square to residual mean square 
98.542\% and 0.6361 (Fig. 7g-j). Finally, the Eudragitcoated optimized bilayer tablet was developed and evaluated. The formulation, thus, met the requirement of providing an immediate release during the first hour and a sustained release action for a period of $8 \mathrm{~h}$ after passing the gastric region.

\section{Conclusion}

The present study demonstrates the successful preparation of the Eudragit-coated chronomodulated time release bilayer tablet of fexofenadine $\mathrm{HCl}$ and montelukast sodium. The aim of the study is to use a $\mathrm{QbD}$ approach to investigate the effect of variables on the CQAs of the bilayer tablet in an effective and economical manner with less number of experiments. The QTPP of the tablet was developed as per the previous studies, and CQAs were selected for the investigation. The fexofenadine $\mathrm{HCl}$-loaded immediate and montelukast sodium-loaded sustained release layers were successfully optimized using a 3-factor, 3-level Box-Behnken design. The optimization model used in the study was successfully validated using ANOVA and diagnostic plots. The optimized formulation was confirmed as per the desirability plots. It was observed that the extended concentration of sodium starch glycolate prompted an increase in disintegration time and a relating increment in drug release. This was due to the swelling property of sodium starch glycolate that leads to a faster release of the tablet constituents. Sodium bicarbonate, being an effervescence agent, also contributed to the faster drug release. However, the effect of sodium starch glycolate was more pronounced than sodium bicarbonate. It was observed that with an increase in the concentration of HPMC, there was a decline in drug release. The HPMC frames a rubbery gel layer around the formulation, which leads to a slow drug release. Similar observations were made for magnesium stearate which is hydrophobic in nature that creates a barrier between the tablet components and the outer aqueous environment leading to a decrease in drug release. The design of the present bilayer tablet successfully provided the immediate release of fexofenadine $\mathrm{HCl}$ and a sustained drug release of montelukast sodium with an initial lag time of $2 \mathrm{~h}$. Thus, the formulation can be fruitful in curbing the menace of nocturnal asthma and providing a high degree of patient compliance.

\footnotetext{
Abbreviation

ANOVA: Analysis of variance; BBD: Box-Behnken design; BD: Bulk density; CQA: Critical quality attributes; DF: Degree of freedom; DoE: Design of experiment; DUREDAS: Dual Release Drug Absorption System; HPMC: Hydroxypropyl methyl cellulose; ICH: International Conference on Harmonisation; PBS: Phosphate buffer saline; PEG: Polyethylene glycol; PRESS: Predicted residual error sum of squares; PVP: Polyvinylpyrrolidone; QbD: Quality by design; QTPP: Quality target product profile; TD: Tapped density
}

\section{Acknowledgements}

The authors would like to thank Dr. Rohit Bisht, Founder and Director, Scholars Paper Lab, Haldwani, Uttarakhand, India, for his guidance in making this manuscript.

\section{Authors' contributions}

All authors have read and approved the manuscript. BS contributed to the research guidance and analytical studies. GS contributed to the formulation evaluation and data analysis. MV contributed to the research guidance and data analysis. SV contributed to the formulation development and evaluation.

\section{Funding}

No funding was availed for the present investigation. This research did not receive any specific grant from funding agencies in the public, commercial, or not-for-profit sectors.

\section{Availability of data and materials}

All data provided in the manuscript is available upon request.

Ethics approval and consent to participate

Not applicable.

\section{Consent for publication}

Non applicable.

\section{Competing interests}

The authors declare that they have no competing interests.

\section{Author details}

'Abhilashi College of Pharmacy, Ner Chowk Road, Ner Chowk, Mandi, Himachal Pradesh 175008, India. 'Department of Pharmaceutical Sciences, Lovely Professional University, Jalandhar - Delhi G.T. Road, Phagwara, Punjab 144411, India. ${ }^{3}$ Abbott Healthcare Pvt Ltd., Baddi, Himanchal Pradesh, India.

Received: 3 August 2019 Accepted: 9 September 2019

Published online: 29 October 2019

\section{References}

1. Xiongbin J (2016) Nocturnal asthma: a special type of asthma. Glob J Allergy 2:3-9

2. Silkoff PE, Martin RJ (1998) Pathophysiology of nocturnal asthma. Ann Allergy Asthma Immunol 81:378-384

3. Turner-Warwick M (1988) Epidemiology of nocturnal asthma. Am J Med 85:6-8

4. Dethlefsen U, Repgas R (1985) Ein neues therapieprinzip bei nachtlichen asthma. Klin Med 80:44-47

5. Hetzel MR, Clark TJ, Branthwaite MA (1977) Asthma: analysis of sudden deaths and ventilatory arrests in hospital. BMJ 1:808-811

6. Cochrane GM, Clark JH (1975) A survey of asthma mortality in patients between ages 35 and 64 in the Greater London hospitals in 1971. Thorax 30:300-305

7. Ali J, Saigal N, Qureshi MJ, Baboota S, Ahuja A (2010) Chronopharmaceutics: a promising drug delivery finding of the last two decades. Recent Pat Drug Deliv Formul 4:129-244

8. Mandal SA, Biswas N, Karim KM, Guha A, Chatterjee S, Behera M, Kuotsu K (2010) Drug delivery system based on chronobiology-a review. J Control Release 147:314-325

9. Abebe A, Akseli I, Sprockel O, Kottala N, Cuitino AM (2014) Review of bilayer tablet technology. Int J Pharm 461:549-558

10. Nirmal J, Saisivam S, Peddanna C, Muralidharan S, Nagrarajan M (2008) Bilayer tablets of atrovastatin calcium and nicotinic acid: formulation and evaluation. Chem Pharm Bull 56:1455-1458

11. Shiyani B, Gattani S, Surana S (2008) Formulation and evaluation of bi-layer tablet of metoclopramide hydrochloride and ibuprofen. AAPS PharmSciTech 9:818-827

12. ICHQ8(R2). The international conference on harmonization of technical requirements for registration of pharmaceuticals for human use, quality guideline Q8(R2) pharmaceutical development. 2009 http://www.ich.org/ fileadmin/Public_Web_Site/ICH_Products/Guidelines/Quality/Q8_R1/Step4/ Q8_R2_Guideline.pdf. (Accessed 2 Aug 2018) 
13. ICH Q9. The international conference on harmonization of technical requirements for registration of pharmaceuticals for human use, $\mathrm{ICH}$ harmonised tripartite guideline Q9 Quality Risk Management. 2005 http:// www.ich.org/fileadmin/Public_Web_Site/ICH_Products/Guidelines/Quality/ Q9/Step4/Q9_Guideline.pdf. (Accessed 2 Aug 2018)

14. ICHQ10. The international conference on harmonization of technical requirements for registration of pharmaceuticals for human use, $\mathrm{ICH}$ harmonised tripartite guideline, Q 10 pharmaceutical quality system. 2008 https://www.ich.org/fileadmin/Public_Web_Site/ICH_Products/Guidelines/ Quality/Q10/Step4/Q10_Guideline.pdf. (Accessed 2 Aug 2018)

15. Narang A, Nayak UY, Roy B, Narayan R (2016) Formulation design of bilayer dual-release tablet composition of fexofenadine $\mathrm{HCl}$ and montelukast sodium. Res J Pharm Tech 9:1410-1416

16. Tak W, Gupta B, Thapa RK, Woo KB, Kim SY, Go TG, Choi Y, Choi JY, Jeong $\mathrm{JH}$, Choi HG, Yong CS, Kim JO (2016) Preparation and optimization of immediate release/sustained release bilayered tablets of loxoprofen using Box-Behnken design. AAPS PharmSciTech 18:1125-1134

17. Shah RB, Tawakkul MA, Khan MA (2008) Comparative evaluation of flow for pharmaceutical powders and granules. AAPS PharmSciTech 9:250-258

18. Govedarica B, Injac R, Dreu R, Srcic RS (2011) Formulation and evaluation of immediate release tablets with different types of paracetamol powders prepared by direct compression. Afr J Pharm Pharmacol 5:31-41

19. Hildebrandt C, Gopireddy SR, Fritsch AK, Profitlich T, Scherlie R, Urbanetz NA (2017) Evaluation and prediction of powder flowability in pharmaceutical tableting. Pharm Dev Technol 13:1-13

20. Shiyani BG, Dholakiya RB, Akbari BV, Lodhiya DJ, Ramani GK (2009) Development and evaluation of novel immediate release tablets of metoclopramide $\mathrm{HCl}$ by direct compression using treated gellan gum as a disintegration-accelerating agent. J Pharm Res 2:1460-1464

21. Bashar A, Alkhalidi A, Alkhatib HS, Khdair AA (2010) Comparative dissolution of diltiazem immediate and extended release products using conventional and innovative dissolution paddles. Open Drug Deliv J 4:48-54

22. Vemula SK (2015) Colon specific drug delivery: effect of eudragit enteric coating on hydroxypropyl methylcellulose matrix tablets of flurbiprofen. J Young Pharm 7:373-383

23. Roychowdhury S, Singh H, Deora G, Sharma S (2014) Formulation, evaluation and optimization of enteric coated tablets of erythromycin stearate by multivariate ANOVA method. AJADD 2:308-319

24. Huang RJ, Wigent JB (2008) Schwartz. Drug-polymer interaction and its significance on the physical stability of nifedipine amorphous dispersion in microparticles of an ammonio methacrylate copolymer and ethylcellulose binary blend. J Pharm Sci 97:251-262

25. Mitra J, Davoud H, Farhad K, Badir DL, Sara A (2011) Preparation and determination of drug-polymer interaction and in-vitro release of mefenamic acid microspheres made of cellulose acetate phthalate and/or ethylcellulose polymers. Iran J Pharm Res 10:457-467

26. Murtada AO, Abdelkarim MA, Huyam AM (2013) The effect of sodium starch glycolate concentration on physical effectiveness of chlorpheniramine tablets. J Pharm Edu Res 4:47-53

27. Ishikawa T, Watanabe Y, Takayama K, Endo H, Matsumoto M (2008) Effect of hydroxylpropylmethyl cellulose (HPMC) on the release profiles and bioavailability of a poorly water-soluble drug from tablets prepared using macrogol and HPMC. Int J Pharm 202:173-178

28. Arefin P, Hasan I, Reza MS (2016) Design, characterization and in vitro evaluation of HPMC K100 M CR loaded fexofenadine HCl microspheres. Springer Plus 5:1-11

29. Uzunovic A, Vranic E (2007) Effect of magnesium stearate concentration on dissolution properties of ranitidine hydrochloride coated tablets. Bosn J Basic Med Sci 7:279-283

30. Khan MA, Chaturvedi SC (2010) Formulation of sustained release zolpidem tartrate matrix tablets through optimization and their evaluation. Asian J Chem 22:4749-4762

31. Thoorens G, Krier F, Leclercq B, Carlin B, Evrard B (2014) Microcrystalline cellulose, a direct compression binder in a quality by design environment-a review. Int J Pharm 473:64-72

32. Desai PM, Liew CV, Heng PWS (2016) Review of disintegrants and the disintegration phenomena. J Pharm Sci 105:2545-2555

33. Zhou Q, Armstrong B, Larson I, Stewart PJ, Morton DA (2010) Improving powder flow properties of a cohesive lactose monohydrate powder by intensive mechanical dry coating. J Pharm Sci 99:969-981

34. Yuksel N, Turkmen B, Kurdoglu AH, Basaran B, Erkin J, Baykara T (2007) Lubricant efficiency of magnesium stearate in direct compressible powder mixtures comprising Cellactose ${ }^{\circledast} 80$ and pyridoxine hydrochloride. FABAD J Pharm Sci 32:173-183

35. Gordon MS (1994) Process considerations in reducing tablet friability and their effect on in vitro dissolution. Drug Dev Ind Pharm 20:0363-9045

36. Rahman MM, Roy S, Hasan S, Alam MA, Jha MK, Ahsan MQ, Ferdaus MJ (2011) Effect of mode of addition of disintegrants on dissolution of model drug from wet granulation tablets. Int J Pharm Sci Res 2:84-92

37. Kitazawa S, Johno I, Ito Y, Teramura S, Okado J (1975) Effects of hardness on the disintegration time and the dissolution rate of uncoated caffeine tablets. J Pharm Pharmacol 27:765-770

\section{Publisher's Note}

Springer Nature remains neutral with regard to jurisdictional claims in published maps and institutional affiliations.

\section{Submit your manuscript to a SpringerOpen ${ }^{\circ}$ journal and benefit from:}

- Convenient online submission

- Rigorous peer review

- Open access: articles freely available online

- High visibility within the field

- Retaining the copyright to your article

Submit your next manuscript at $\boldsymbol{\nabla}$ springeropen.com 